\title{
A study of psychiatric comparability in subjects with malignancy
}

\author{
Gayathri Narayanasamy
}

\section{Introduction}

Psychiatric oncology is the field of medicine concerned with frequent mental and affective problems that we come across in sufferers of cancer and their loved ones. It encompasses the study of pain due to malignancy and its palliative care, mental illness screening, quality of life, communication skills for physicians in handling difficult questions and breaking bad news, and counselling. It is also concerned with management of staff stress and burnout among health care providers (Chaturvedi, 2012).

Depression and anxiety occur in a substantial proportion (15-25\%) of cancer patients (Agarwal, 2010). Because of methodological issues and difficulties in distinguishing depressive symptomatology from that of malignancy, the real frequency of depressive disorders in sufferers of malignancy may be much higher (Pasquini \& Biondi, 2007). In spite of the lack of clarity of the contributory link between malignancy and depressive disorders, a relationship has been often cited (Kissane, 2009).

Depression comprises $4.4 \%$ of the worldwide illness burden taken as a whole, just like IHD and diarrhoea (WHO 2000). Disability adjusted life years for depressive disorder is going to be more than for malignancy or retroviral disease (Ustun, 1999). 15\% of recently diagnosed cancer patients meet criteria for MDD (Grassi \& Rosti, 1999). Sharpe (2004) reported 8\% prevalence of MDD in cancer patients, most of them with inactive disease. Prieto (2005) reported 9\% prevalence in inpatients with haematological cancers. Coyne (2004) reported same prevalence in breast cancer patients. Ell (2005) found 24\% prevalence among low-income women with cancer. Okamura (2002) found $22 \%$ prevalence of MDD at time of first recurrence of carcinoma of breast. Depression and anxiety was found to be 33\% prevalent at the time of diagnosis, $15 \%$ at 1 year after diagnosis, and $45 \%$ following recurrence (Burgess, 2005).

Maximum number of studies has been done in breast cancer patients (Prieto, 2005, Zabora, 1997, Kadan-Lottick, 2005, Korfage, 2006). Symptoms of depression in women getting treatment for early stage breast carcinoma are not associated with objective variables related to cancer (Bardwell, 2006). Ashbury (2003) reported that failing to diagnose Major Depressive Disorder (MDD) in sufferers of cancer leads to:

1. Decline in their quality of life

2. Longer duration of stay in hospital

3. Non-compliance with treatment plan

The possible predictors of anxiety and depressive disorders in patients with cancer are:

1. Demographic factors - age, sex, education, employment, income, and marital status, proximity to family, patient's social network, life stresses and coping.

2. Illness-related factors - type of cancer, time since diagnosis, cancer stage and grade, and presence of symptoms, effects of treatment, attitudes and beliefs about cancer, comorbid medical illness. Literature suggests that the impact of malignancy on depression is buffered by social support so that depression risk is lesser in those with good social support. (Mathieson, 1996)

There is not much literature regarding the predictors of depression and anxiety in cancer patients in India. We studied the demographic and illness factors related to depression and anxiety in this population. We hope that this might be helpful in developing better informed interventions for ameliorating the quality of life of sufferers of malignancy who are at danger of developing anxiety and/or depression.

\section{Review Of Literature}

Cancer is a very traumatic experience involving the following issues which predispose to depression and/or anxiety:

i. Encountering the likelihood of mortality

ii. Body image and self-esteem alterations

iii. Apprehension of invasive procedures and pain

iv. Familial, occupational and societal role changes

v. Interruption of life plans

All these are significant matters to be handled. Also, the course of the illness and treatment adherence may be affected by depression. The cost and frequency, the harm caused, and the uncertainty with regard to 
diagnosis and treatment due to depression among sufferers of cancer make it a main concern for scientific enquiry (Pasquini and Biondi, 2007).

Strategies employed to cope; feelings of loss, conscious efforts at adapting and changeover affect clinical manifestations of depression in cancer patients (Brennan, 2001). Anxiety and depression are often undetected and hence left unmanaged in sufferers of malignancy, ensuing in a major harmful impact on quality of life and outcome of illness (Berard, 2001).

Physicians are prone to underestimate symptoms suggestive of depression in patients with malignancy. If physicians are trained to look out for the more dependable cognitive symptoms, such as lack of pleasure seeking, remorse, suicidality and despair, their assessment may be improved. It would be useful to employ screening instruments and brief follow-up interviews to find out sufferers with depression (Passik, 1998).

Making a diagnosis of depressive disorder in an advanced malignancy is made intricate by the actuality that a lot of symptoms of malignancy have common characteristics with depressive somatic symptomatology.

Approaches to somatic symptoms (Bailey, 2005):-

1. Inclusive model- Somatic symptoms are taken into account regardless of cause, while diagnosing MDD in cancer patients.

2. Substitution model (Endicott, 1984) - Somatic symptoms are substituted by non-somatic symptoms of depression.

3. Exclusive model- Somatic symptoms are disregarded as diagnostic criteria.

For evaluating depressive disorder in sufferers of advanced malignancy, Endicott prefers the substitution of somatic symptoms with physiological symptoms:

Somatic/physical symptoms:

1. Weight/appetite change

2. Insomnia

3. Loss of energy/fatigue

4. Decreased concentration

Psychological symptoms which are substituted:

1. Sad demeanour, tearfulness

2. Alogia, asociality

3. Negative outlook on life, lamenting, self-pity

4. Restriction of affect, reduced reactivity (Endicott J, 1984).

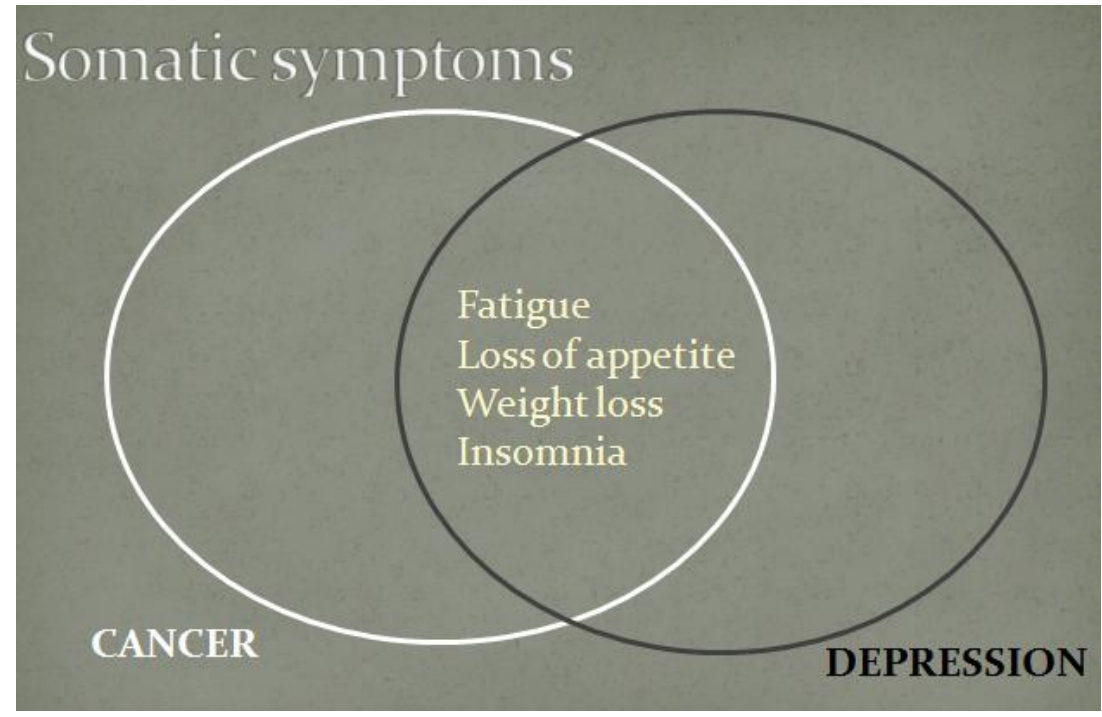

The somatic symptoms are probably responsible for the alterations in the Beck Depression Inventory in cancer patients than the affective symptoms (Wedding, 2007).

The centuries-old stigma attached to malignancy did not allow the diagnoses to be told to the patients. This led to the avoidance of any chance to come to know of the ways in which cancer sufferers coped with their disease. Also, a second and similarly long-held stigma attached to mental disorder has been another obstacle and this has prevented sufferers from being able to recognize their emotional struggles and to go for counselling. The progress of psychological oncology has been slow because of this "double stigma" (Holland, 2003). 


\section{Prevalence}

In a study, $24 \%$ of a group of sufferers of malignancy had severe depression, $18 \%$ had moderate depression. Depressive symptoms not meeting criteria for major depression were present in another $14 \%$. Important predictors were greater degree of physical debility, other negative life events and poor social support (Bukberg, 1994).

Estimated frequency of depressive disorder in various subgroups of sufferers of malignancy, in a systematic review, was as follows: outpatients- $5 \%$ to $16 \%$; admitted patients- 4 to $14 \%$; mixed sample including both patients receiving treatment on outpatient basis as well as those admitted- 4 to $11 \%$ and palliative care- 7 to $49 \%$. Lower prevalence was found by studies which employed specialist interviewers (clinical psychologists and psychiatrists) (Walker, 2013).

In a study on women with newly diagnosed carcinoma breast, the following findings were reported. Clinically significant distress was present in $41 \%$ of the subjects. Major depression was present in $11 \%$ (60\% of whom had moderately severe to severe depression) and posttraumatic stress disorder was present in $10 \%$ subjects. These emotional symptoms had a marked impact on the functioning of the patients. Though $56 \%$ of the depressed patients were already on psychotropic medications, they still did not remit. (Hegel, 2006)

Psychiatric referral patterns at two Japanese cancer hospitals showed that the most commonly referred were patients with lung cancer (19\%), followed by carcinoma breast (13\%) and malignancy of the head and neck $(10 \%)$. More than $50 \%$ of the sufferers had cancer recurrence or metastasis, pain was present in $60 \%$. The most frequent reasons for psychiatric referral were assessment by mental health professional (35\%), insomnia (19\%), fear/anxiety (18\%), and depressive disorders (18\%). Adjustment disorder (34\%), acute confusional state (17\%) and major depressive disorder (14\%) were the most common psychiatric diagnoses. (Akechi, 2001)

Adjustment disorder or major depression was seen in about $17 \%$ of the subjects in one study among recently found out sufferers of malignancy of head and neck. Nicotine dependence was present in about 33\%. Psychological distress had significant association with stage of cancer and living alone. (Kugaya, 2000)

DIFFERING VIEW: A study looked for anxiety and depression in patients with prostate or other urogenital cancers. The highest anxiety mean scores were recorded at the start of the hospital stay (i.e. in stage T1). From stage T2 to T4, the prevalence of anxiety was similar to that of the general population, and even less than that found in cardiac patients. Lower prevalence of depression was found compared to the general population. Higher psychological distress was found in those who were younger, and in those who were receiving radio- or chemotherapy. Based on their findings, the authors concluded that professional psychiatric help was not required by most prostate cancer patients and that some patients may benefit from such help, especially at the beginning of the hospital stay. (Hinz, 2009)

Adjustment disorder with depressed mood or depressive disorder is found in about $25 \%$ of hospitalized cancer patients. Important predictors are mood disorder or alcoholism in the past, cancer stage, presence of pain, medications which produce depressive symptoms, concurrent illnesses which lead to depressive symptoms (Massie MJ, 1990).

Another study reported that emotional distress that was clinically noteworthy (Hospital Anxiety and Depression score $\geq 15$ ) was present in about $1 / 4$ th of the study sample of 3071 patients. Important determinants were age less than 65 yrs, female gender, and type of cancer and extent of disease (Strong, 2007).

A study done in a tertiary care hospital among gynaecological oncology outpatients found that nearly $26 \%$ had depression and 17\% had anxiety (Mendonsa and Appaya, 2010).

In an outpatient oncology setting, about $14 \%$ were found to have depression. They found that the existing health care system had managed to identify and treat only $14 \%$ of the interviewed depressed patients and they highlighted the need for suitable screening tools (Berard, 1998).

It is hard to assess mood disorder when a cancer sufferer is faced with recurring threats to existence, receiving treatments for malignancy, has fatigue or aches. Many studies since the 1960s have found the prevalence of depression between $0-38 \%$ and that of depression spectrum syndromes as being $0-58 \%$. This wide variance is due to different conceptualisations of depression, different defining criteria for depression, different methodological approaches in measuring depression and different populations being studied. Cancers with highest depression prevalence were upper digestive tract (22-57\%), pancreas (33-50\%), mammary (1.5-46\%) and pulmonary (11-44\%) (Massie, 2004).

In another study, $40 \%$ of carcinoma lung sufferers had anxiety and $25 \%$ were depressed, and this was found to be equal among hospitalized patients as well as those attending the outpatient clinic. (Du-Quiton, 2010).

\section{Effect of depression on cancer}

Most studied cancers in this regard are malignant melanoma, CA lung, and renal carcinoma and CA breast. The mortality risk is raised when depressive symptoms co-occur with malignancy (Onitilo, 
2006). The 1 year and 3 year case fatality rate was increased significantly by the occurrence of depression in sufferers of hematologic malignancy following stem cell transplantation (Prieto, 2005).

In sufferers of lung malignancy, reduced survival times are foretold by emotional distress and depressive coping style (Faller, 1999).

\section{How depression affects cancer prognosis:}

1. As a direct neuroimmunologic consequence

2. Depression may lead to poorer compliance to the treatment given for cancer

The Minnesota Multiphasic Personality Inventory (MMPI) clearly differentiates the psychological distinction among the two extreme set of cancer sufferers- those with rapidly progressing disease and those with a far longer expectancy (Blumberg, 1954).

Psychosocial factors like social support, stress, emotional expression, depression and personality have been found to influence the incidence and progression of cancer. This relationship has been proposed to be mediated by mechanisms such as changes in diet, exercise, and circadian rhythms; differences in treatment received; and endocrinologic and neuroimmunologic physiological changes (Spiegel and Kato, 1996).

There is a profound stimulating effect of stress on the growth rate of an established cancer (Blumberg, 1954). The cell-mediated immunity, which protects an individual against cancer, may be affected by depression. The impaired host defense mechanisms may pave the way for neoplastic cells to proliferate and spread out of control. Increased IL-6 plasma levels were associated with MDD in cancer patients (Musselman, 2001; Jehn, 2006). Social support is protective against IL-6 elevation in patients with advanced malignancy of the ovary \& IL-6 appears to be a marker of health related quality of life (Constanzo, 2005). Therefore, IL-6 is a biomarker of depressive disorder in sufferers of malignancy.

In case of severe depressive disorder preceding malignancy, the depressive illness may present an additional risk (Kronfol, 1982; Linn, 1982).

The course of cancer and treatment compliance is also severely impacted upon by depressive disorders (Pasquini and Biondi, 2007)

Depression And Cancer Mortality: Studies have found that the diagnosis of depression and more severity predicted increased mortality in cancer patients (Pinquart and Duberstein, 2010). Mental anguish was a forerunner of death due to malignancy, particularly in pulmonary malignancy (Hamer, 2009).

In one study among patients with advanced non-small cell lung cancer (NSCLC), the median survival time in the depressed group was significantly shorter than that of the non-depressed group. The mortality risk in the group with depression was twice that seen in the group without depression. The result shows that depression at the starting stage of cancer therapy predicts decreased survival in sufferers of advanced non-small cell lung cancer (Chen, 2011).

Depressive disorder foretold reduced survival in sufferers of recently detected non-small cell lung cancer in metastatic phase. In spite of the fact that early palliative care (EPC) was linked with more reduction in depressive symptomatology at 12 weeks, the study findings did not support the premise that the survival benefit which was seen to be due to EPC was a consequence of the treatment of depression (Pirl, 2012).

DISSENTERS: A nationwide Danish cohort study, carried out over a period of 24 years, found that their findings did not support the premise that depressive disorder separately raises cancer possibility, but they emphasized the detrimental effects of depressive symptomatology on aspects of day-to-day life (Dalton, 2002). Another study found no evidence of an increased risk of cancer in patients with depression and/or anxiety for over a decade (Friedman, 1990).

Depressive disorder is linked to inferior quality of life, suppression of immune reaction and reduced survival in sufferers of malignancy (Williams and Dale, 2006).

\section{Relationship of various parameters to depression and anxiety in cancer Role of aging:}

Growing old was associated with decreased anguish, decreased apprehension, and improved psychological quality of life. At the same time, growing old was linked to increased depression in these sufferers of malignancy (Nelson, 2009).

The frequency of anxiety and depression in sufferers of malignancy was notably influenced by age upto 40 years (Jadoon, 2010).

Depression frequently manifests in a different way both in sufferers of malignancy as well as in old age. Hence a tailored and customized way of evaluation should be used when making a diagnosis and managing these persons (Weinberger, 2009). 
Compared to any other psychopathological variable studied; disease has a greater independent role (Fafouti, 2010).

In a study, the only variables found to affect distress and depression were higher socioeconomic status and female gender respectively (Pandey, 2006).

\section{Effect of being aware of diagnosis:}

Psychological distress was higher in those who knew their cancer diagnosis (Tavoli, 2007).

Mental and emotional well-being depends very much upon the issues regarding culture and the manner in which information is communicated to sufferers of malignancy (Chowdhury, 2011).

Regardless of the type or phase of cancer, it may be important to recognize and manage somatic symptoms in order to achieve improved quality of life and functioning (Kroenke, 2010).

Patients detected to have an anxiety disorder were more expected to be of female gender, of lesser age, and have a poorer status of physical performance (Spencer, 2010).

Those patients with a past history of alcohol abuse/dependence or mood disorder, later stages of malignancy, pain under poor control, and therapy using drugs or concurrent diseases that cause depression are at utmost risk of developing depressive disorder (Massie, 1990).

The chances of elevated scores of the Center for Epidemiologic Studies-Depression Scale (CES-D) were notably decreased in patients aged more than 50 years in comparison with those whose age was less than or equal to 50 years. The score was also lesser in patients with greater levels of social support and in patients in employment. Men were more to be expected to have depressive disorder indicated by higher CES-D scores. Awareness of sociodemographic features will help the physician to identify those persons who have an increased risk of associated depressive symptomatology (Reisine, 2005).

Nearly $33 \%$ of long-term survivors of malignancy ( 5 years + ) go on to harbour fears of recurrence, fears of developing yet another malignancy, and fears that some of their symptoms may be due to malignancy. Health anxieties related to malignancy are an important predictor of both anxiety and depression. The largely unfailing predictor of mental anguish is optimistic/pessimistic disposition, with lesser malignancy-associated health anxieties, and lesser depression and anxiety, in persons with dispositional optimism. All said and done, for most of them, physical or psychological quality of life is not radically compromised (Deimling, 2006).

Quality of life is predicted by 4 major variables: contentment with support of family doctor, malignancy severity, sufferer's gender, and malignancy type. Mental state was predicted by 3 main factors: anorexia, support of family doctor, sufferer's gender (Mathieson, 1996).

HADS depression score was significantly correlated with fatigue, nausea, sleep disturbances, distress, and memory, loss of appetite, drowsiness, dry mouth and sadness (Arun, 2011).

In one study, long term survivors of NSCLC were studied regarding their quality of life. It was found that hopeful survivors formed the majority (71\%), and the experience of malignancy was seen as leading to constructive existential changes by $50 \%$ of the survivors. Sixty percent had more than one condition showing that co-morbidity was frequent; a CES-D score of more than 16 was found in $22 \%$ indicating distressed mood. $76 \%$ had been smoking previously. A prospective target for intervention is comprised of the predictors of poorer quality of life which are robustly related to distressed mood (Sarna, 2002).

Among non-small cell lung cancer (NSCLC) and small cell lung cancer (SCLC) sufferers, sufferers with SCLC had thrice higher frequency of depressive disorder than those with NSCLC. The most vital risk factor was impairment of function; for every increase on the functional impairment score, depressive symptoms rose by 41 percent. Major independent predictors were load of somatic symptoms prior to treatment, fatigue and performance status rated by physician. Histological subtype was not an independent predictor (Hopwood, 2000).

The most depressed and anxious sufferers of lung malignancy are those who have repeated and long duration waking periods at night and repeated and long duration sedentary periods during day. The anxiety and/or depression scores are directly proportional to the severity of disruption of the circadian rhythm (DuQuiton, 2010).

Depressive disorder was linked to female sex and performance status being low. $1 / 3^{\text {rd }}$ of sufferers of newly detected non-small cell lung cancer had anxiety and depression. This was linked to reduced score on health-related quality of life questionnaires, and compliance to therapy and bad prognosis were independently linked to depression (Arrieta, 2013).

Depressive disorder is frequent and persistent in sufferers of pulmonary malignancy, more so in those with more relentless symptoms or limitation of function. Therefore, palliation must include the crucial element of screening for psychological problems and managing them appropriately.

\section{Role of personality and coping styles}

More cognitive distortions and maladaptive assumptions were present in the group with depressive symptomatology. The prime coping mechanism which was employed by subjects in the group 
without depressive symptomatology was fighting spirit, while the mechanisms used to cope in the group with depressive symptomatology were hopelessness/helplessness, being preoccupied / being worried and fatalistic coping style (Alcalar, 2012).

Existing research suggests that malignancy sufferers' adjustment may be constructively impacted upon by coping through spiritual and religious means (Jenkins, 1995).

It is important to survey the patients' personalities in order to grasp their QOL accurately (Nakada, 1996).

Mental factors which have strong association with increased depressive risk are personality characteristics like neuroticism, and coping approaches such as anxious preoccupation, hopelessness / helplessness and low fighting spirit. Depressive symptomatology was robustly associated with temperamental traits and mechanisms employed to cope, and employing tools for screening to recognise these variables might be helpful for planning preventive (Shimizu, 2012).

\section{Effect of cancer stigma}

Sufferers who felt or experienced the stigma of malignancy were 2.5 times more expected to have depressive disorder than sufferers with optimistic disposition. In spite of quantum leaps made in the field of medicine and greater survival rates, malignancy survivors still felt stigmas about malignancy, and it was notably linked to depressive symptomatology. These results stress upon the requirement for the medical fraternity and health care providers to give more notice to stigma about malignancy which sufferers may be expected to face during therapy (Cho, 2013).

\section{Anxiety and depression screening in malignancy}

Many studies till date which have examined the existence of anxiety and depression in sufferers of malignancy have used the Hospital Anxiety and Depression Scale (HADS) (Moorey, 1991; Kugaya, 2000). The HADS is an easy to administer, self-rated instrument and is efficient in screening for depressive and anxious symptomatology, even in early stages of malignancy (Berard, 2001). It has been found that the HADS, along with the Impact of Event Scale's intrusion subscale, can be useful to detect chances of tardy development of depressive and anxious symptomatology in sufferers of malignancy (Nordin, 1999).

Yet another screening instrument found to be adequate for use in patients with cancer is the Beck Depression Inventory -II (BDI-II) (Warmenhoven, 2011)

\section{Prediction of depression and anxiety following detection of malignancy}

An investigation was done to inspect the likelihood of predicting depressive and anxiety disorders 6 months after detection of malignancy, based on scores of depressive and anxious symptomatology, mechanisms employed to cope and subjective anguish associated with the detection of cancer. Patient anxiety and depression close to the detection explained nearly $35 \%$ of the variation in depression and anxiety symptoms seen after 6 months. For finding out sufferers who are likely to develop tardy depression and anxiety, the Impact of Events Scale- Intrusion Subscale and the Hospital Anxiety and Depression Scale may be useful tools (Nordin, 1999).

Yet another study found that age less than 65 years, being employed or not, family support, and several symptoms due to malignancy or treatment independently predicted depressive disorder (Agarwal, 2010).

Gender, race, co-morbid conditions, physical functioning, social functioning, and symptoms were important predictors of depression. Both greater number of symptoms and greater limitation of functional performance in somatic and social domains were associated with increase in symptoms of depression (Kurtz, 2002).

Functional performance in the emotional domain is a vital predictor of the need for social support. Women are emotionally more affected than men and need more psychosocial support (Ernstmann, 2009).

More severe symptoms of depression, being of young age and being single- all these increase the chances for sufferers of metastatic malignancy of being referred for psychosocial supportive care (Ellis, 2009).

Feminine sex was linked to the existence of depressive and anxious symptomatology. Lesser tumour grade on the WHO classification of grade of malignancy, academic accomplishment being lower, and past history of mental disorder were significant predictors of depressive and anxious symptomatology. Depressive disorder alone was significantly linked to relationship status and history of current/past physical disease (Arnold, 2008).

\section{Effects of cancer on depression}

Epidermal Growth Factor Receptor mutations were linked to reduced severity of depressive disorder and decreased probabilities of depression in sufferers of non-small cell lung cancer in metastatic stage. 
This was found out on the basis of screening for affective symptoms done prior to obtaining the genotyping findings (Pirl, 2011).

Affective disorders are promoted by the physiologic substrate afforded by inflammation (Raison \& Miller, 2003). Features of cytokine induced sickness syndrome in cancer include fatigue, loss of appetite \& weight, cognitive disturbances, decreased motor activity and libido.

Links among state of nutrition, systemic inflammation, and subjective mental suffering are evidence of their shared fundamental pathophysiology and go on to impress upon the need for an anti-cachectic approach which is holistic (Giannousi, 2012).

\section{Effects of chemotherapy}

In a study, $13.7 \%$ patients who were undergoing chemotherapy experienced depression. Important predictors were education level and symptoms like pain, insomnia, nausea, anorexia and fatigue (Akechi, 2012).

Chemotherapy is associated with many adverse effects which negatively affect the quality of life of sufferers of malignancy of the breast. Similar is the case with adjuvant hormonal therapies (Montazeri, 2008).

In a study among patients undergoing chemotherapy, anxiety was found in about $15 \%$ and depression in about $16 \%$ subjects. They found that high social status influenced presence of distress and female gender influenced the prevalence of depression (Pandey, 2006).

The anxiety state is significantly higher in patients treated with cytotoxic drugs than in operated and increased during the time of treatment. In patients treated with cytotoxic drugs, anxiety as a feature, increased in the course of treatment, and in patients treated surgically it remained stable (Nalepa, 1996).

$\mathrm{Li}$ and colleagues (2012) found in their study that during chemotherapy, the patients had significant anxiety.

\section{Effects of radiotherapy}

Psychological distress was found to be highly prevalent (30\% of cases) in persons receiving radiotherapy for malignancy of the head and neck (Bjordal, 1995) This is true even before beginning treatment and it increases significantly during treatment (Chen, 2009).

In another study, 33\% of patients who had completed a course of radiotherapy had depression (LloydWilliams, 1994)

Patients' views about radiotherapy: Most patients believed that radiation is inherently damaging and carcinogenic. They thought that it was bad news if they required radiotherapy. It was seen as curative by few. Post treatment interviews showed more depression and anxiety than pre treatment interviews. This meant that the procedure was a stressful one. However, it is ironic that the concepts of very serious adverse effects and futility of this treatment among both doctors and lay people are largely false (Peck and Boland, 1972).

A study looked for anxiety and depression in patients with prostate or other urogenital cancers. Higher psychological distress was found in those were receiving radiotherapy (Hinz, 2009).

\section{Objectives}

\section{Aim And Hypothesis} in a tertiary hospital inpatient population.

\section{Secondary Objective(s)-}

1. To find the risk factors for depression and anxiety in lung cancer patients.

2. To determine the extent to which depression and anxiety can be predicted on the basis of measures of subjective distress and social support.

\section{Study centre}

\section{Materials And Methods}

We recruited the participants for the study from the inpatients admitted in the Dept. of Medical Oncology, Rajiv Gandhi Govt. General Hospital, Chennai.

All the study participants were of different stages of lung cancer who were planned for chemotherapy or already undergoing it.

\section{Patient selection}

We interviewed the patients by the bedside during their inpatient admission. We informed them about the nature of the assessment- to elicit psychological distress- being done as a part of a research study and obtained their informed consent to proceed with the assessment. 


\section{Inclusion criteria}

\section{Exclusion criteria}

All patients diagnosed with lung cancer irrespective of stage or grade

a. Patients not willing to participate

b. Patients already diagnosed as having any mental illness before the onset of cancer

c. Patients who were not physically fit enough to complete the study

d. Patients with severe cognitive impairment screened by MMSE

\section{Screening}

We used the Hospital Anxiety and Depression Scale (HADS) to screen the presence of anxiety and/or depression. A score of 8 or above on the anxiety and/or depression subscales denoted case status.

\section{Sample size}

We conducted the data collection over a period of three months. The sample size was 93.

\section{Assessment of patients}

We made two types of assessments:

1. For those scoring 8 or more on the HADS subscales, all the questionnaires mentioned below were administered.

2. For those scoring less than 8 on the HADS subscales, all the questionnaires mentioned below were administered, except for the Hamilton Depression Rating Scale (HAM-D/HDRS) and the Hamilton Anxiety Rating Scale (HAM-A).

\section{Sociodemographic data}

We recorded the patients' socio-demographic variables and illness variables on a proforma specially designed for the study (Appendix I).

Phase of illness

Phase of illness was classified as: phase 1-newly diagnosed persons, phase 2-persons in first remission, phase 3-persons following the development of a second primary lesion without metastasis, and phase 4-persons with metastatic disease (Agarwal, 2010).

\section{Instruments}

1. Karnofsky Performance Status Scale (KPS) - The Karnofsky Performance Status (KPS) is a widely used method to assess the functional status of a patient. It was introduced by David A. Karnofsky and Joseph H. Burchenal in 1949. Originally entitled Performance Status, the term Karnofsky Performance Status was coined at a later date, and renamed after the author of its creation. It is a standard way of measuring the ability of cancer patients to perform ordinary tasks. The Karnofsky score runs from 100 to 0 , where 100 is "perfect" health and 0 is death. KPS may be used to determine a patient's prognosis, to measure changes in a patient's ability to function, or to decide if a patient could be included in a clinical trial. (Karnofsky, 1949)

2. Fagerstrom Test for Nicotine Dependence - It is a revision of the Fagerström Tolerance Questionnaire (FTQ; Fagerström, 1978). It has 6 items which includes items like time to first cigarette of the day, smoking in forbidden places and number of cigarettes smoked per day, etc., Scoring: 0-2: very low dependence 3-4: low dependence

5: medium dependence

6-7: high dependence

8-10: very high dependence

(Heatherton, 1991)

3. Hospital Anxiety and Depression Scale (HADS) - Originally developed by Zigmond and Snaith in 1983 as a tool for the detection of anxiety and depression in people with physical health problems. It is a fourteen item scale. Seven of the items relate to anxiety and seven relate to depression. Each item on the questionnaire is scored from 0-3 and this means that a person can score between 0 and 21 for either anxiety or depression. The scale used is a Likert scale and therefore the data returned from the HADS is ordinal. (Zigmond, 1983)

4. Hamilton Depression Rating Scale (HAM-D/HDRS) - It was developed by Hamilton in 1960 to monitor the severity of major depression. The ratings can be completed in 15 to 20 minutes. Reliability is good to excellent, including internal consistency and inter-rater assessments. Validity appears good based on correlation with other depression symptom measures.

Scoring:- 7 or less: normal

8-13: mild 
14-18: moderate

19-22: severe

23 and above: very severe

(Hamilton, 1960)

5. Hamilton Anxiety Rating Scale (HAM-A): A psychological questionnaire used by clinicians to rate the severity of a patient's anxiety. It was originally published by Max Hamilton in 1959. It contains 14 symptom-oriented questions. Each of these symptoms is given a severity rating, from not present (scored as 0 ) to very severe (scored as 4). The clinician must choose the possible responses to each question by interviewing the patient and by observing the patient's symptoms. Administration time is about 10-20 minutes. Each question is scored 0-4. A total score of $0-17$ is considered to be mild, 18-25 mild to moderate, and 26-30 moderate to severe. Totals above 30 are rare, but indicate very severe anxiety (Hamilton, 1959).

6. Social Support Questionnaire - It was developed by Sarason et al. in 1983. It measures the perceived social support in individuals. The short form has six items. Each item has two parts. The first part assesses the number of available others the individual feels he/she can turn to in times of need in each of a variety of situations and gives the Number or Perceived Availability Score. The second part measures the individual's degree of satisfaction with the perceived support available in that particular situation (Sarason, 1987).

7. Presumptive Stressful Life Events Scale (PSLES) - It was introduced by Gurmeet Singh in 1984. It is the Indian adaptation of the Holmes and Rahe Stress Scale validated and standardized for our population. It consists of 51 stressful life events classified as desirable, undesirable, ambiguous, personal and impersonal. (Singh, 1984)

8. WHOQOL-BREF (World Health Organization Quality of Life - BREF) - I t is a scale for measuring the quality of life. It has 4 domains- physical health, psychological health, social relationships and environment. (WHO, 2004)

9. Sheehan Disability Scale (SDS) - It is a self-report scale which assesses functional impairment in three interrelated domains- work/school, social and family life. It is a 10-point visual analog scale. The total of the three domains gives the global functional impairment measure that ranges from 0 (unimpaired) to 30 (highly impaired) (Sheehan, 1996). In patients suffering from cancer, the impact of somatic symptom burden on disability and healthcare use can be quantified by using the Sheehan Disability Scale (SDS). This is important because somatic symptoms have to be recognized and managed in order to improve quality of life and functional status of these patients (Kroenke et al, 2010).

10. Satisfaction with Life Scale (SLS) - It was introduced by Ed Diener. It is a short 5-item instrument designed to measure global cognitive judgments of satisfaction with one's life. Each item is rated from 1-7. (Diener, 1985)

\section{Data analysis and Statistics}

Data analysis was done using the SPSS software version 20.

Statistical tests employed were-

1. Chi-square test

2. Independent sample t-test

3. Pearson's correlation

4. One way analysis of variance (ANOVA)

\section{Results}

Ninety three consecutive cases were included in the study to assess the prevalence of depressive and anxiety symptoms in the group of inpatients admitted in the Medical Oncology Department, Rajiv Gandhi Government General Hospital, Chennai for non-small cell lung cancers (NSCLCs) of various stages.

The breakup of the sample consisted of 43 patients diagnosed as cases when the cut-off score of HADS more than or equal to 8 was taken. A total of 93 patients were screened to obtain this sample with the rest 50 being controls.

Those scoring just below the cut-off score of 8 were further evaluated for the presence of depression and/or anxiety using the Structured Clinical Interview for DSM-IV Axis I Disorders (SCID). Of that group of 50 patients none was found to fulfil the criteria for a diagnosis of depression and/or anxiety. This was done so as not to miss out any cases screened by the HADS.

\section{Sample demographics}

The demographic profiles of the sample are given below: 
Table 1: Gender

\begin{tabular}{|c|c|c|c|c|c|c|}
\hline \multirow{3}{*}{ Sex } & \multicolumn{4}{|c|}{ Group } & \multicolumn{2}{|c|}{ Total } \\
\hline & \multicolumn{2}{|c|}{ Control } & \multicolumn{2}{|c|}{ Case } & \multirow[t]{2}{*}{$\mathbf{N}$} & \multirow[t]{2}{*}{$\%$} \\
\hline & $\mathrm{N}$ & $\%$ & $\mathrm{~N}$ & $\%$ & & \\
\hline Men & 38 & 76.0 & 29 & 67.4 & 67 & 72.0 \\
\hline Women & 12 & 24.0 & 14 & 32.6 & 26 & 28.0 \\
\hline Total & 50 & 100.0 & 43 & 100.0 & 93 & 100.0 \\
\hline
\end{tabular}

\begin{tabular}{|l|l|}
\hline Chi-Square Test & P-Value \\
\hline Pearson Chi-Square & 0.359 \\
\hline
\end{tabular}

Men comprised $72 \%$ of the sample while $28 \%$ were women. The gender distribution did not differ significantly between the case and control groups.

\section{Chart 1}

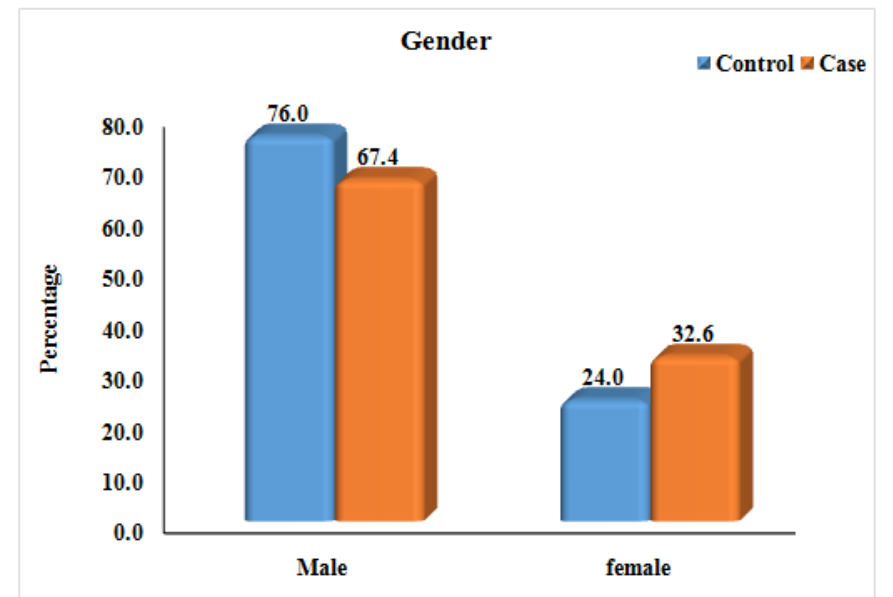

The two groups did not differ significantly in gender distribution.

Table 2: Age

\begin{tabular}{|l|c|}
\hline Mean & 52.72 \\
\hline Median & 52.00 \\
\hline Mode & 55 \\
\hline Std. Deviation & 12.024 \\
\hline
\end{tabular}

The mean age of the sample was 52.72 years with a standard deviation of 12.024 years.

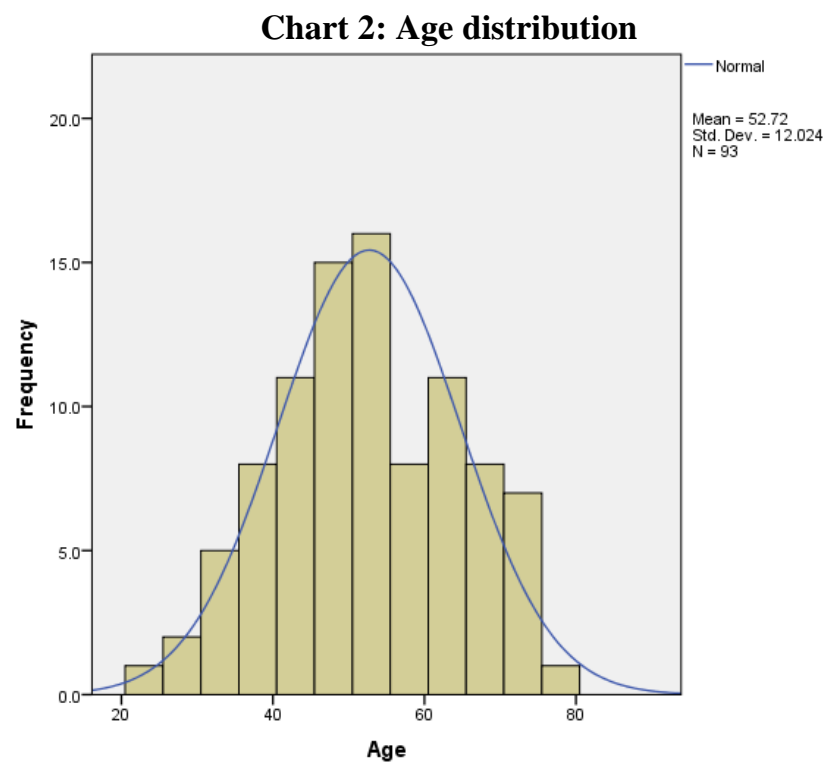

The median age of the sample was 52 years and the age distribution followed normal distribution. 
Table 3: Age comparison between the groups

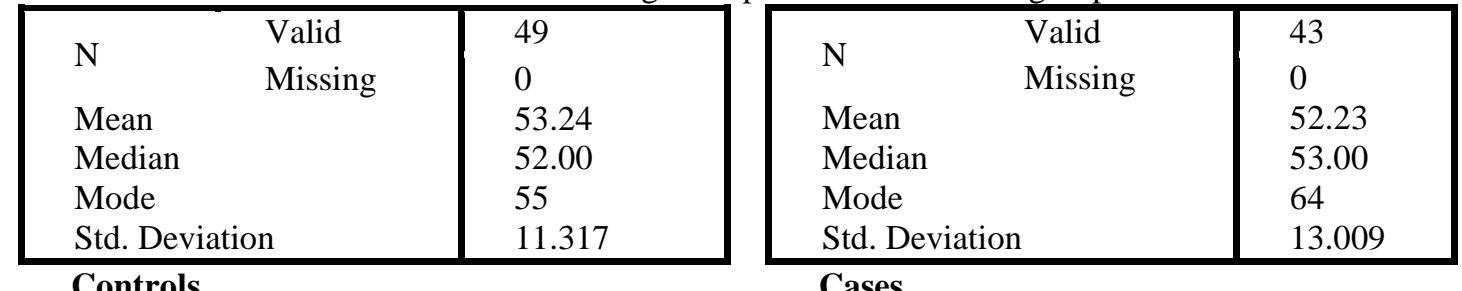

The two groups did not differ significantly in age distribution.

Chart 3: Age distribution among cases and controls

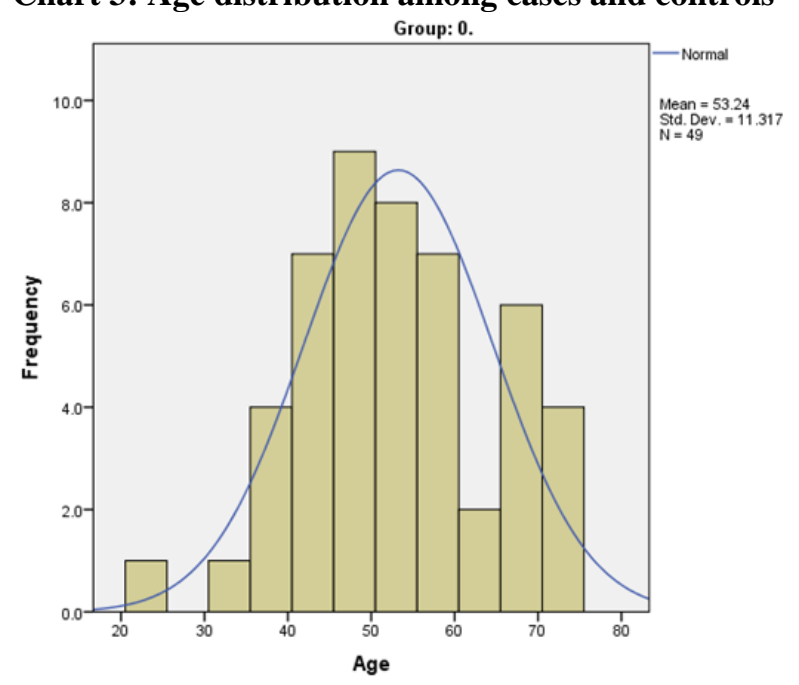

Controls

The two groups did not differ significantly in age distribution.

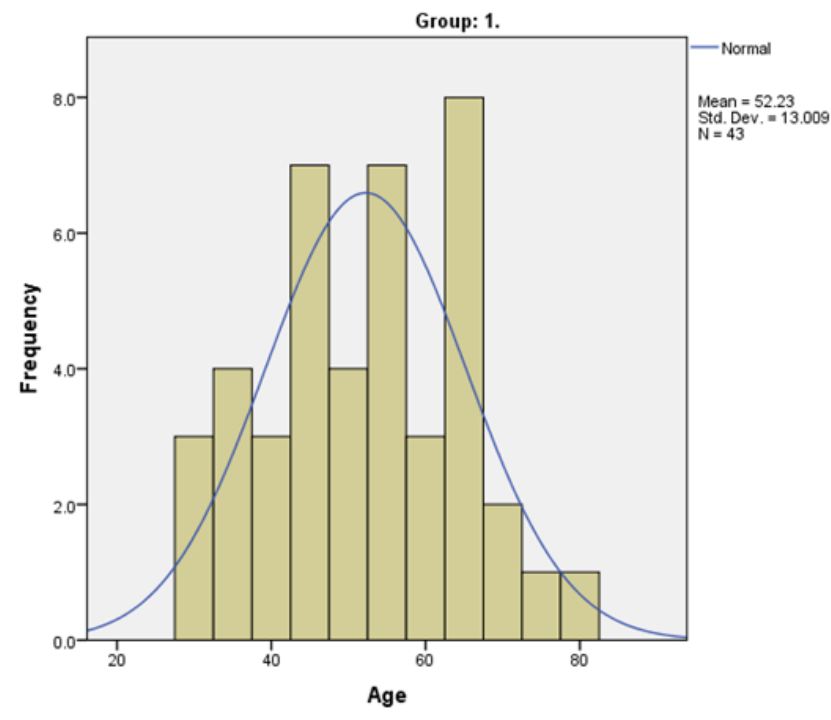

Cases

Table 4: Residence

\begin{tabular}{|c|c|c|c|c|c|c|}
\hline \multirow{2}{*}{ Address } & \multicolumn{4}{|c|}{ Group } & \multicolumn{3}{c|}{ Total } \\
\cline { 2 - 6 } & \multicolumn{2}{|c|}{ Control } & \multirow{2}{*}{ Case } & \multirow{2}{*}{$\%$} \\
\cline { 2 - 7 } & $\mathbf{N}$ & $\mathbf{\%}$ & $\mathbf{N}$ & $\mathbf{\%}$ & & 48.4 \\
\hline Rural & 23 & 46.0 & 22 & 51.2 & 45 & 19.4 \\
\hline Semi urban & 9 & 18.0 & 9 & 20.9 & 18 & 32.3 \\
\hline Urban & 18 & 36.0 & 12 & 27.9 & 30 & 100.0 \\
\hline Total & 50 & 100.0 & 43 & 100.0 & 93 & 10 \\
\hline
\end{tabular}




\begin{tabular}{|l|l|}
\hline Chi-Square Test & P-Value \\
\hline Pearson Chi-Square & 0.705 \\
\hline
\end{tabular}

Case and control group did not differ significantly in terms of place of residence.

Chart 4:

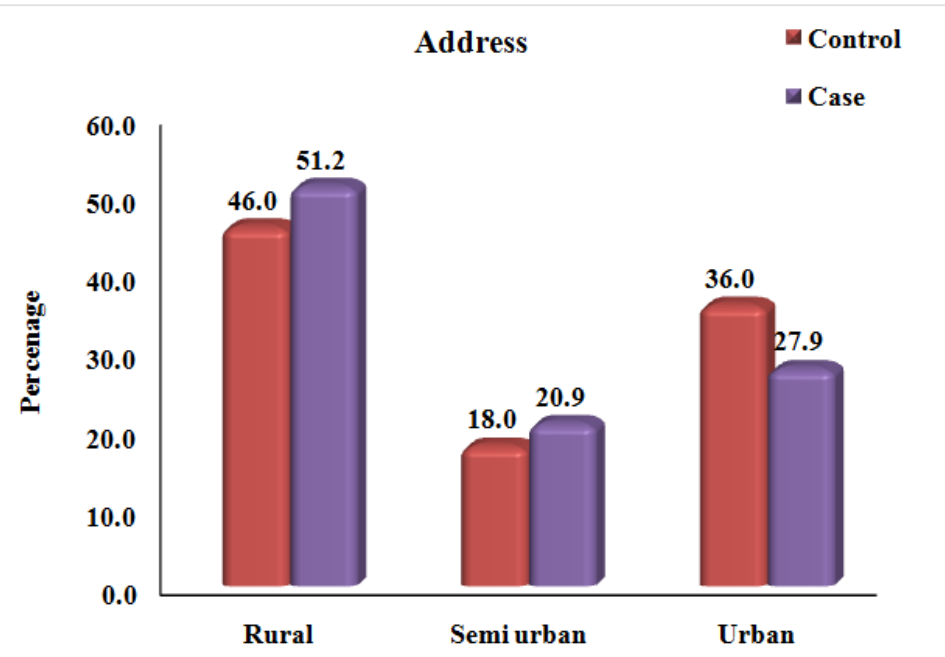

Most of the subjects in both the groups resided in rural areas.

Table 5: Education

\begin{tabular}{|c|c|c|c|c|c|c|}
\hline \multirow{3}{*}{ Education } & \multicolumn{4}{|c|}{ Group } & \multicolumn{2}{|c|}{ Total } \\
\hline & \multicolumn{2}{|c|}{ Control } & \multicolumn{2}{|c|}{ Case } & \multirow{2}{*}{$\mathbf{N}$} & \multirow{2}{*}{$\%$} \\
\hline & $\mathbf{N}$ & $\%$ & $\mathbf{N}$ & $\%$ & & \\
\hline Illiterate & 16 & 32.0 & 15 & 34.9 & 31 & 33.3 \\
\hline Primary school & 9 & 18.0 & 9 & 20.9 & 18 & 19.4 \\
\hline Middle school & 15 & 30.0 & 10 & 23.3 & 25 & 26.9 \\
\hline High school & 10 & 20.0 & 9 & 20.9 & 19 & 20.4 \\
\hline Total & 50 & 100.0 & 43 & 100.0 & 93 & 100.0 \\
\hline \multicolumn{3}{|c|}{ Chi-Square Test } & & \multicolumn{2}{|c|}{ P-Value } & \\
\hline \multicolumn{4}{|c|}{ Pearson Chi-Square } & \multicolumn{2}{|c|}{0.905} & \\
\hline
\end{tabular}

Case and control group did not differ significantly in terms of educational qualification.

Chart 5:

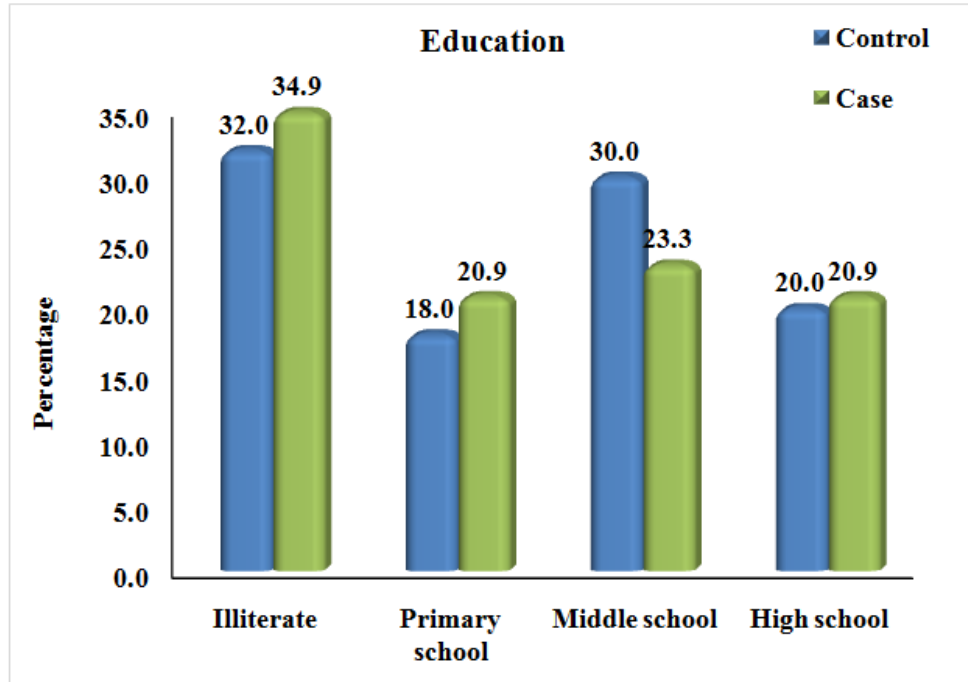

Most of the subjects in both groups had never attended school. 
Table 6: Occupation

\begin{tabular}{|c|c|c|c|c|c|c|}
\hline \multirow{3}{*}{ Occupation } & \multicolumn{4}{|c|}{ Group } & \multicolumn{2}{|c|}{ Total } \\
\hline & \multicolumn{2}{|c|}{ Control } & \multicolumn{2}{|c|}{ Case } & \multirow{2}{*}{$\mathbf{N}$} & \multirow{2}{*}{$\%$} \\
\hline & $\mathbf{N}$ & $\%$ & $\mathbf{N}$ & $\%$ & & \\
\hline Unemployed & 9 & 18.0 & 5 & 11.6 & 14 & 15.1 \\
\hline Unskilled worker & 15 & 30.0 & 10 & 23.3 & 25 & 26.9 \\
\hline Semiskilled worker & 1 & 2.0 & 6 & 14.0 & 7 & 7.5 \\
\hline Skilled worker & 6 & 12.0 & 9 & 20.9 & 15 & 16.1 \\
\hline Clerical, shop-owner, farmer & 15 & 30.0 & 10 & 23.3 & 25 & 26.9 \\
\hline Semi-profession & 4 & 8.0 & 3 & 7.0 & 7 & 7.5 \\
\hline Total & 50 & 100.0 & 43 & 100.0 & 93 & 100.0 \\
\hline
\end{tabular}

\begin{tabular}{|l|l|}
\hline Chi-Square Test & P-Value \\
\hline Fisher's Exact Test & 0.233 \\
\hline
\end{tabular}

No significant difference was found between the two groups in terms of occupation.

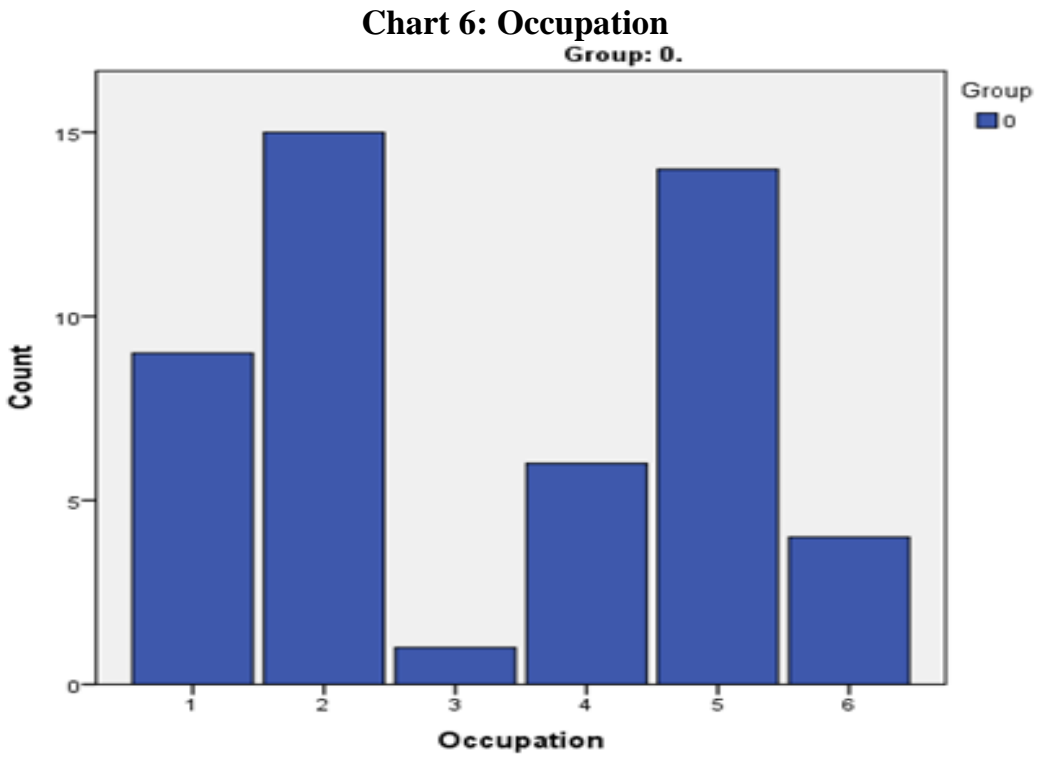

Controls

Unskilled work was the most common occupation in both groups.

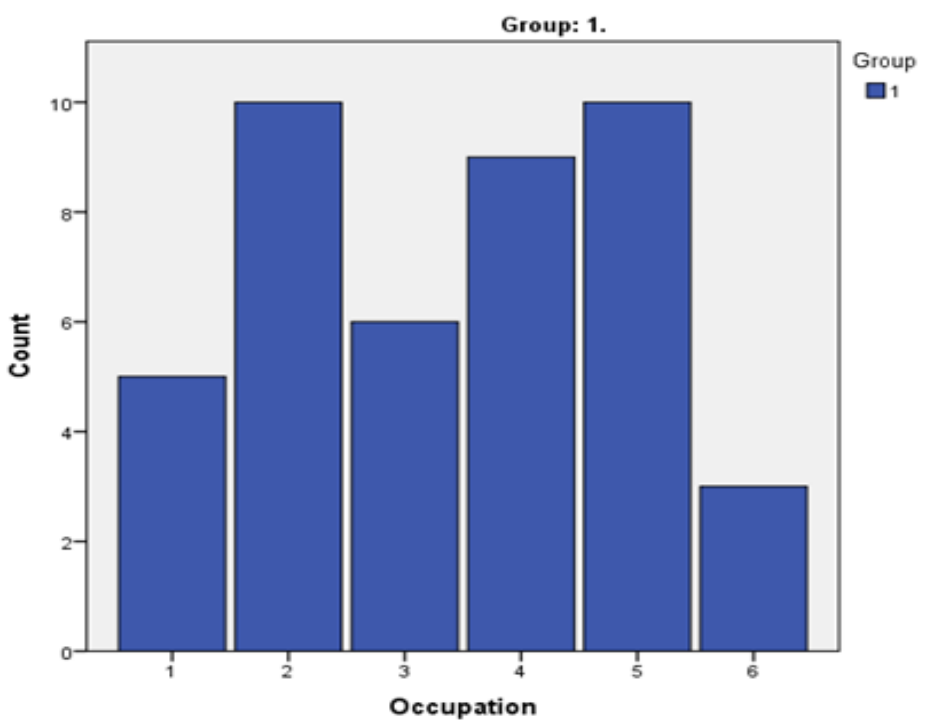

\section{Cases}

1=unemployed, $2=$ unskilled worker, $3=$ semiskilled worker, $4=$ skilled worker, $5=$ clerical, shop-owner, farmer, $6=$ semi-profession, $7=$ profession 
Table 7: Marital status

\begin{tabular}{|c|c|c|c|c|c|c|}
\hline \multirow{3}{*}{ Marital status } & \multicolumn{4}{|c|}{ Group } & \multicolumn{2}{|c|}{ Total } \\
\hline & \multicolumn{2}{|c|}{ Control } & \multicolumn{2}{|c|}{ Case } & \multirow{2}{*}{$\mathbf{N}$} & \multirow{2}{*}{$\%$} \\
\hline & $\mathbf{N}$ & $\%$ & $\mathbf{N}$ & $\%$ & & \\
\hline Single & 7 & 14.0 & 4 & 9.3 & 11 & 11.8 \\
\hline Married & 37 & 74.0 & 28 & 65.1 & 65 & 69.9 \\
\hline Separated & 1 & 2.0 & 7 & 16.3 & 8 & 8.6 \\
\hline Widowed & 5 & 10.0 & 4 & 9.3 & 9 & 9.7 \\
\hline Total & 50 & 100.0 & 43 & 100.0 & 93 & 100.0 \\
\hline
\end{tabular}

\begin{tabular}{|c|c|}
\hline Chi-Square Test & P-Value \\
\hline Fisher's Exact Test & 0.102 \\
\hline
\end{tabular}

The two groups did not differ significantly in terms of marital status.

Chart 7:

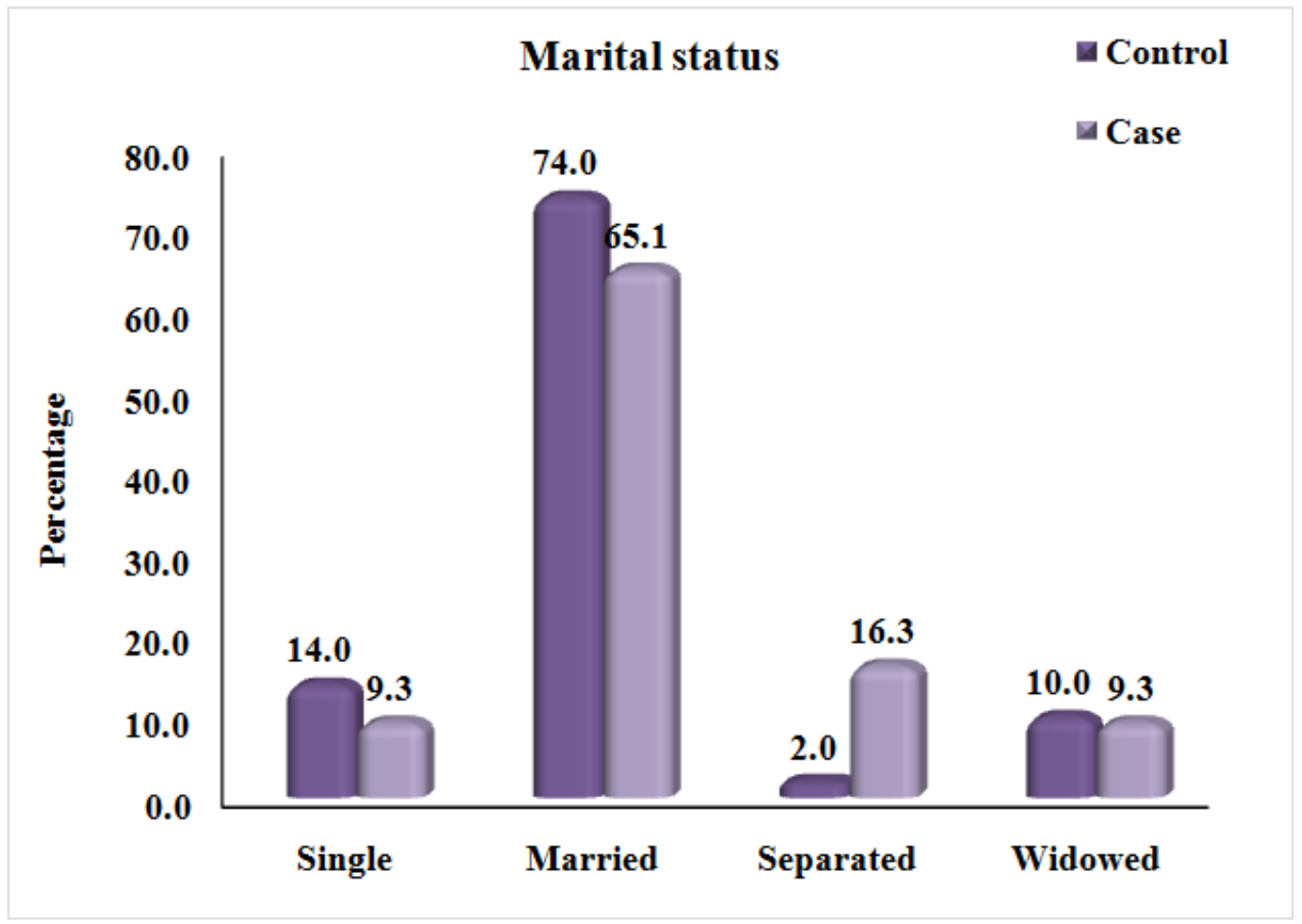

Most of the subjects in both the groups were married.

Table 8: Family type

\begin{tabular}{|c|c|c|c|c|c|c|}
\hline \multirow{2}{*}{ Family type } & \multicolumn{3}{|c|}{ Group } & \multicolumn{3}{c|}{ Total } \\
\cline { 2 - 7 } & \multicolumn{2}{|c|}{ Control } & N & \multirow{2}{*}{ Case } \\
\cline { 2 - 7 } & $\mathbf{N}$ & $\mathbf{N}$ & 4 & 9.3 & 5 & 5.4 \\
\hline Staying alone & 1 & 2.0 & 22 & 51.2 & 43 & 46.2 \\
\hline Nuclear & 21 & 42.0 & 7 & 16.3 & 16 & 17.2 \\
\hline Extended & 9 & 18.0 & 10 & 23.3 & 29 & 31.2 \\
\hline Joint & 19 & 38.0 & 43 & 100.0 & 93 & 100.0 \\
\hline Total & 50 & 100.0 & & & \\
\hline
\end{tabular}

\begin{tabular}{|l|l|}
\hline Chi-Square Test & P-Value \\
\hline Fisher's Exact Test & 0.244 \\
\hline
\end{tabular}

The two groups did not differ significantly in terms of family type. 
Chart 8: Family type

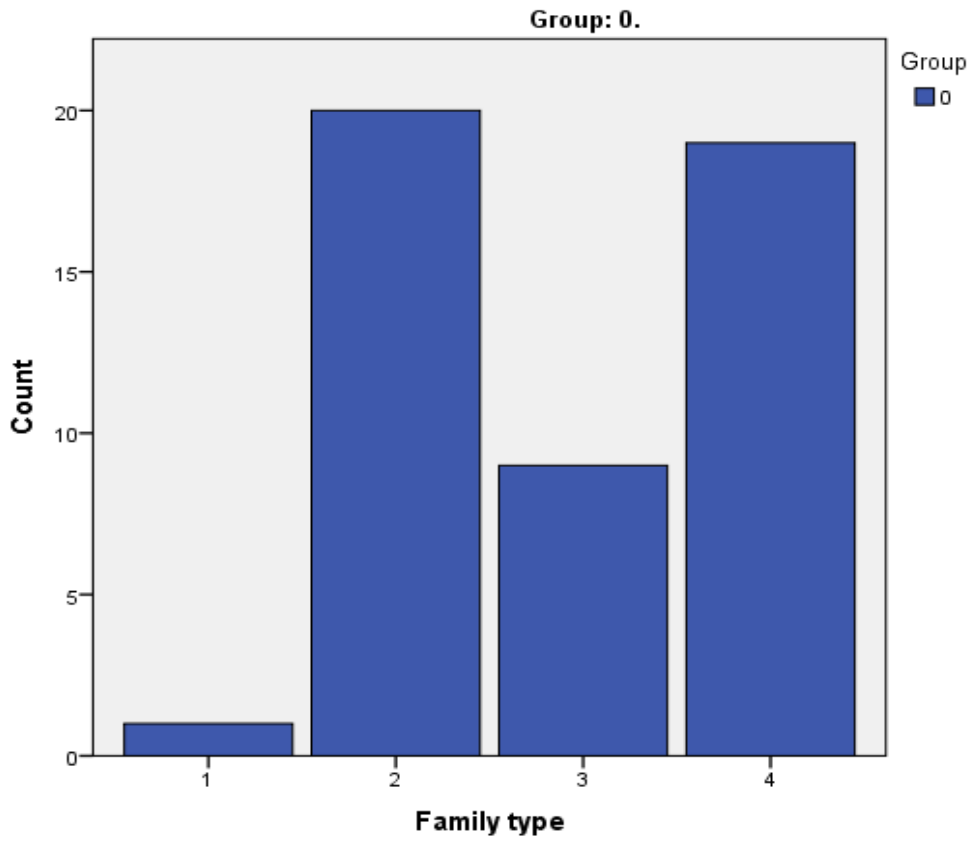

\section{Controls}

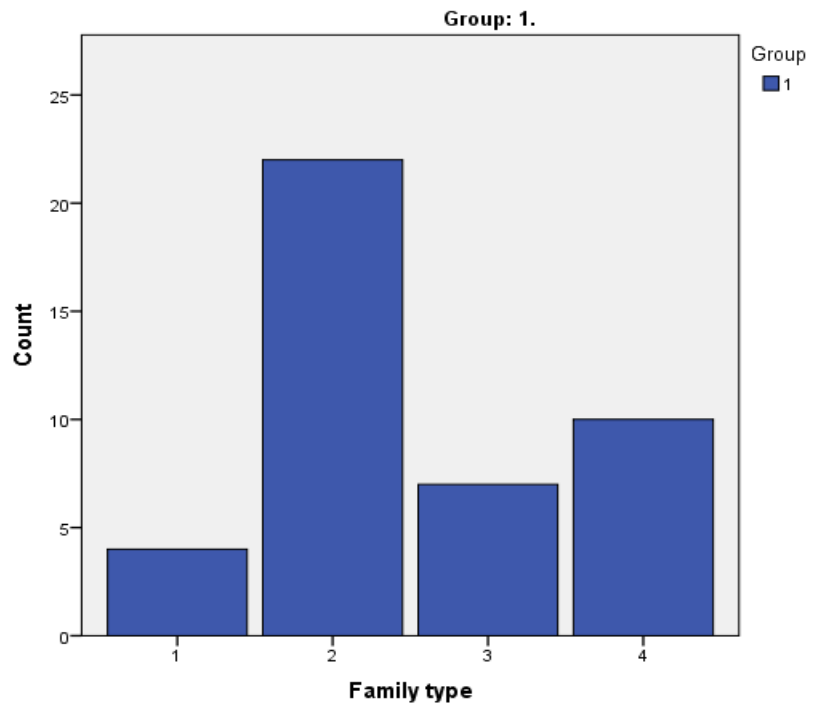

Cases

$1=$ staying alone, $2=$ nuclear, $3=$ extended, $4=$ joint, Nuclear family was most common in both case and control groups.

Table 9: Language

\begin{tabular}{|c|c|c|c|c|c|c|}
\hline \multirow{3}{*}{ Language } & \multicolumn{4}{|c|}{ Group } & \multicolumn{2}{|c|}{ Total } \\
\hline & \multicolumn{2}{|c|}{ Control } & \multicolumn{2}{|c|}{ Case } & \multirow{2}{*}{$\mathbf{N}$} & \multirow{2}{*}{$\%$} \\
\hline & $\mathbf{N}$ & $\%$ & $\mathbf{N}$ & $\%$ & & \\
\hline Tamil & 42 & 84.0 & 33 & 76.7 & 75 & 80.6 \\
\hline Telugu & 4 & 8.0 & 4 & 9.3 & 8 & 8.6 \\
\hline Urdu & 2 & 4.0 & 4 & 9.3 & 6 & 6.5 \\
\hline Malayalam & 1 & 2.0 & 2 & 4.7 & 3 & 3.2 \\
\hline Nepali & 1 & 2.0 & 0 & .0 & 1 & 1.1 \\
\hline Total & 50 & 100.0 & 43 & 100.0 & 93 & 100.0 \\
\hline
\end{tabular}

\begin{tabular}{|l|l|}
\hline Chi-Square Test & P-Value \\
\hline Fisher's Exact Test & 0.690 \\
\hline
\end{tabular}

The two groups did not differ significantly in terms of language distribution 


\section{Chart 9: Language}

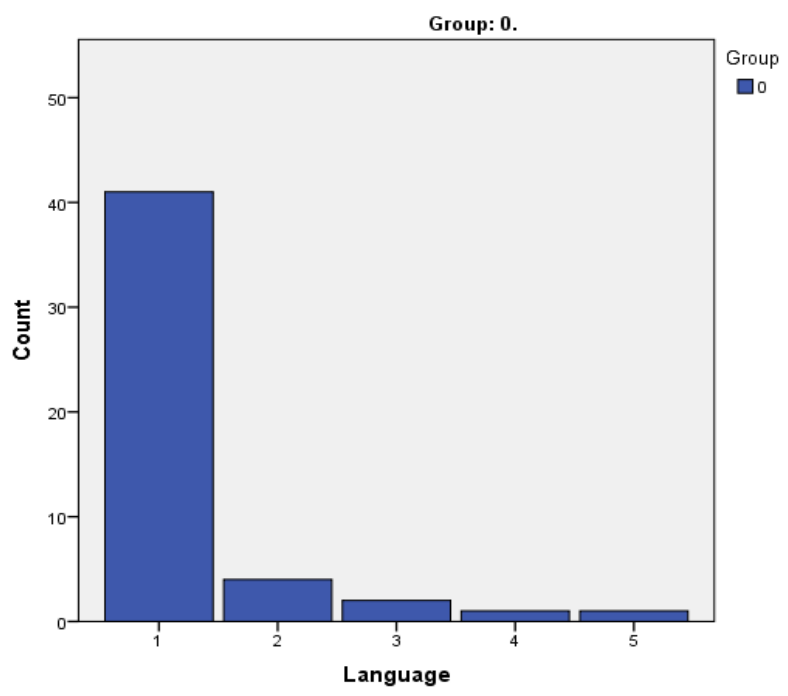

\section{Controls}

$1=$ tamil, $2=$ telugu, $3=$ =urdu, 4=malayalam, $5=$ nepali

Tamil was the most common language spoken in both groups.

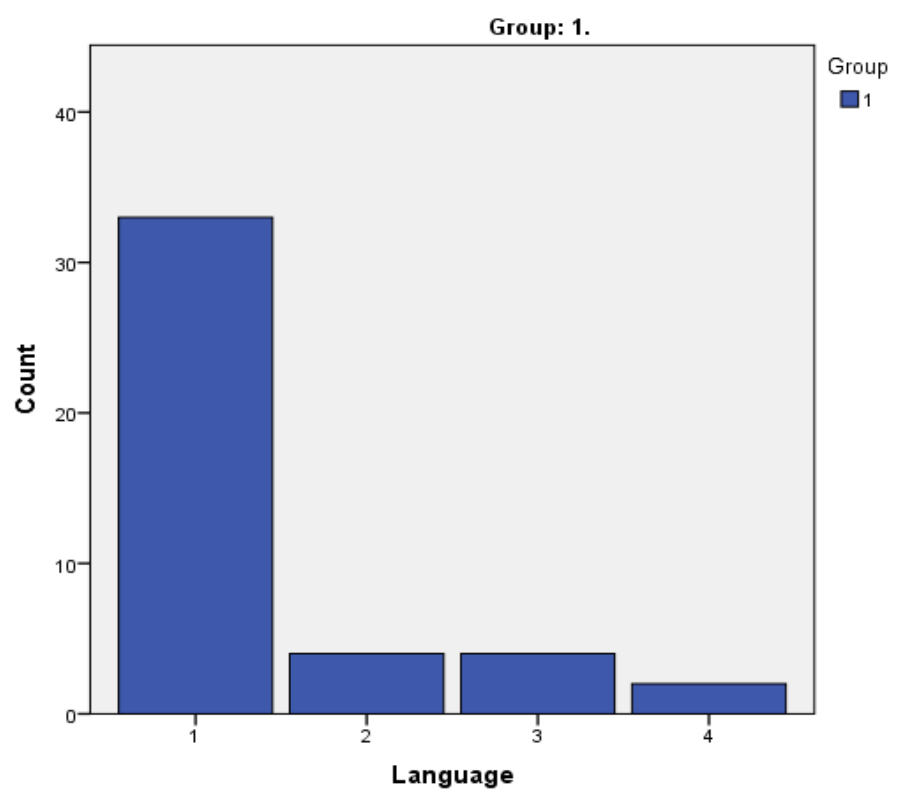

\section{Cases}

Table 10: Religion

\begin{tabular}{|c|c|c|c|c|c|c|}
\hline \multirow{3}{*}{ Religion } & \multicolumn{4}{|c|}{ Group } & \multicolumn{2}{|c|}{ Total } \\
\hline & \multicolumn{2}{|c|}{ Control } & \multicolumn{2}{|c|}{ Case } & \multirow{2}{*}{$\mathbf{N}$} & \multirow{2}{*}{$\%$} \\
\hline & $\mathbf{N}$ & $\%$ & $\mathbf{N}$ & $\%$ & & \\
\hline Hindu & 47 & 94.0 & 35 & 81.4 & 82 & 88.2 \\
\hline Islam & 2 & 4.0 & 4 & 9.3 & 6 & 6.5 \\
\hline Christian & 1 & 2.0 & 4 & 9.3 & 5 & 5.4 \\
\hline Total & 50 & 100.0 & 43 & 100.0 & 93 & 100.0 \\
\hline
\end{tabular}

\begin{tabular}{|l|l|}
\hline Chi-Square Test & P-Value \\
\hline Fisher's Exact Test & 0.181 \\
\hline
\end{tabular}

The two groups did not differ significantly in terms of religion. 


\section{Chart 10: Religion}

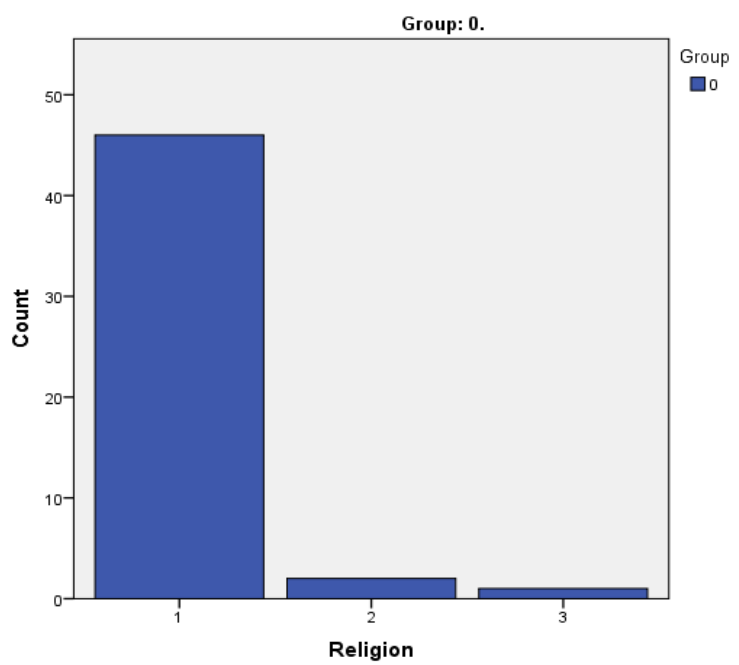

\section{Controls}

1=Hinduism, 2=Islam, $3=$ Christianity

Hinduism was the most common religion practised among both groups.

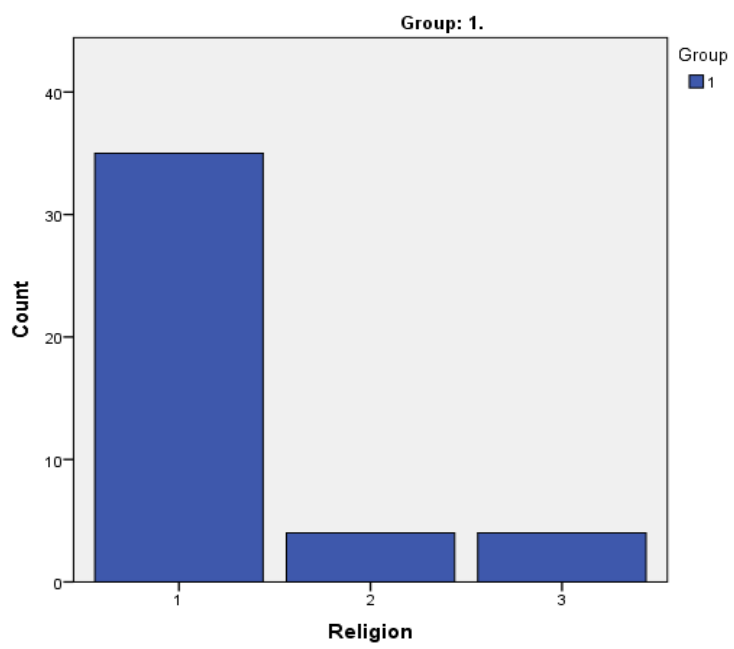

\section{Cases}

Table 11: Mean time since diagnosis

\begin{tabular}{|l|l|}
\hline Controls & 24 months \\
\hline Cases & 16 months \\
\hline
\end{tabular}

The mean time since diagnosis in the control group was 24 months whereas in the case group it was 16 months.

Table 12:

\begin{tabular}{|c|c|c|c|c|c|c|}
\hline \multirow{3}{*}{ Phase of illness (1-4) } & \multicolumn{4}{|c|}{ Group } & \multicolumn{2}{|c|}{ Total } \\
\hline & \multicolumn{2}{|c|}{ Control } & \multicolumn{2}{|c|}{ Case } & \multirow{2}{*}{$\mathbf{N}$} & \multirow{2}{*}{$\%$} \\
\hline & $\mathbf{N}$ & $\%$ & $\mathbf{N}$ & $\%$ & & \\
\hline Phase-1 & 17 & 34.0 & 14 & 32.6 & 31 & 33.3 \\
\hline Phase-2 & 18 & 36.0 & 11 & 25.6 & 29 & 31.2 \\
\hline Phase-3 & 6 & 12.0 & 4 & 9.3 & 10 & 10.8 \\
\hline Phase-4 & 9 & 18.0 & 14 & 32.6 & 23 & 24.7 \\
\hline Total & 50 & 100.0 & 43 & 100.0 & 93 & 100.0 \\
\hline
\end{tabular}

\begin{tabular}{|l|l|}
\hline Chi-Square Test & P-Value \\
\hline Fisher's Exact Test & 0.428 \\
\hline
\end{tabular}

There was no significant difference between the two groups in terms of phase of illness. 


\section{Chart 11:}

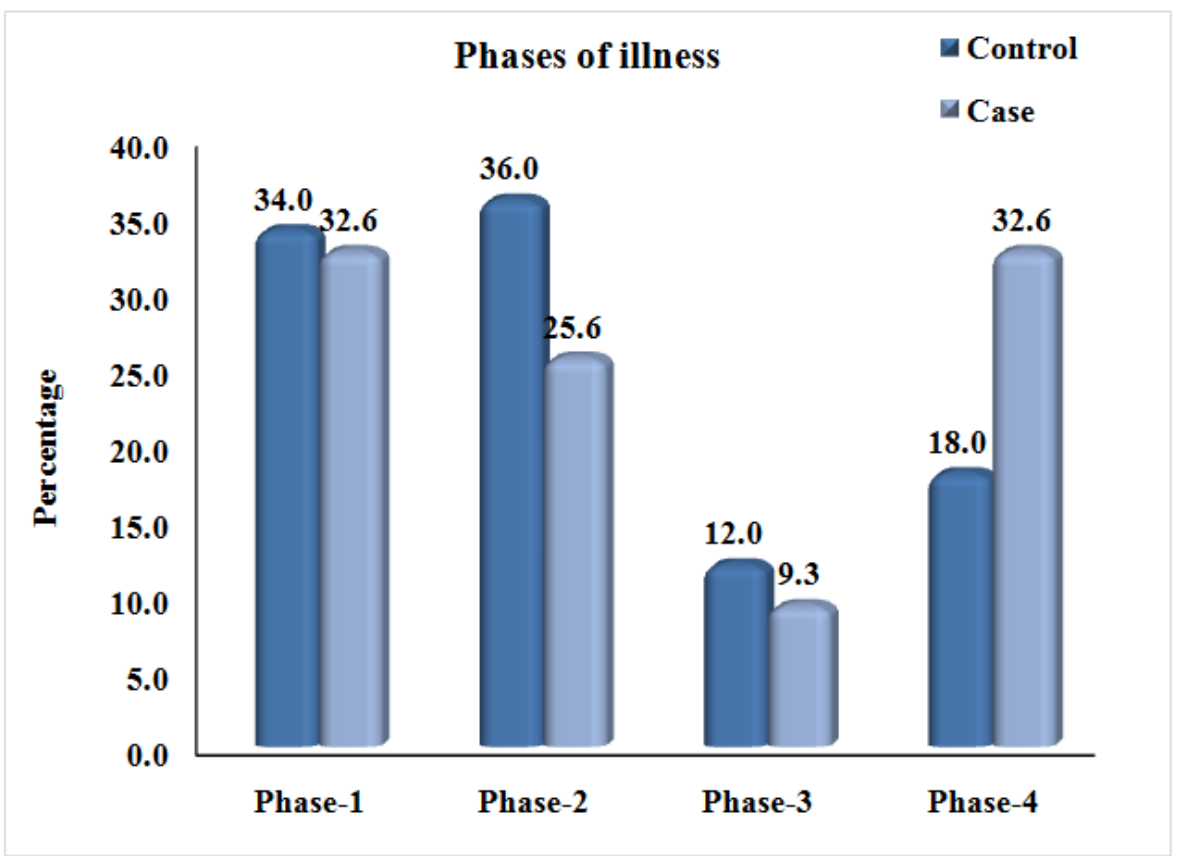

2 of illness.

Most of the subjects in the case group were in phase 4 whereas most in the control group were in phase

Independent samples T-Test to compare the mean value between groups

\begin{tabular}{|c|c|c|c|c|c|}
\hline & Group & $\mathbf{N}$ & Mean & Std. Deviation & P-Value \\
\hline \multirow{2}{*}{ Age } & Control & 50 & 53.14 & 11.225 & \multirow{2}{*}{0.719} \\
\hline & Case & 43 & 52.23 & 13.009 & \\
\hline \multirow{2}{*}{ Time since diagnosis (months) } & Control & 50 & 23.58 & 30.470 & \multirow{2}{*}{0.201} \\
\hline & Case & 43 & 16.26 & 23.199 & \\
\hline \multirow{2}{*}{$\begin{array}{c}\text { Karnofsky Performance Status Score } \\
(0-100)\end{array}$} & Control & 50 & 70.80 & 11.400 & \multirow{2}{*}{0.883} \\
\hline & Case & 43 & 70.47 & 10.225 & \\
\hline \multirow{2}{*}{ FTND } & Control & 50 & 4.36 & 3.729 & \multirow{2}{*}{0.579} \\
\hline & Case & 43 & 3.93 & 3.686 & \\
\hline \multirow{2}{*}{ HADS Anxiety Score } & Control & 50 & 1.48 & 2.197 & \multirow{2}{*}{$<0.001$} \\
\hline & Case & 43 & 11.07 & 4.426 & \\
\hline \multirow{2}{*}{ HADS Depression Score } & Control & 50 & 2.16 & 2.444 & \multirow{2}{*}{$<0.001$} \\
\hline & Case & 43 & 12.65 & 4.105 & \\
\hline \multirow{2}{*}{ HAM-D } & Control & 50 & .00 & .000 & \multirow{2}{*}{$<0.001$} \\
\hline & Case & 43 & 23.77 & 10.982 & \\
\hline \multirow{2}{*}{ HAM-A } & Control & 50 & .00 & .000 & \multirow{2}{*}{$<0.001$} \\
\hline & Case & 43 & 21.58 & 13.713 & \\
\hline \multirow{2}{*}{ SSQ Number } & Control & 50 & 3.9368 & 2.95457 & \multirow{2}{*}{0.301} \\
\hline & Case & 43 & 3.3433 & 2.55312 & \\
\hline \multirow{2}{*}{ SSQ Satisfaction } & Control & 50 & 4.4362 & 1.55612 & \multirow{2}{*}{0.980} \\
\hline & Case & 43 & 4.4271 & 1.88575 & \\
\hline \multirow{2}{*}{$\begin{array}{c}\text { Presumptive Stressful Life Events } \\
\text { Score }\end{array}$} & Control & 50 & 91.10 & 44.140 & \multirow{2}{*}{0.031} \\
\hline & Case & 43 & 110.28 & 39.472 & \\
\hline \multirow{2}{*}{ Total WHOQOL-BREF } & Control & 50 & 73.92 & 17.145 & \multirow{2}{*}{0.001} \\
\hline & Case & 43 & 96.79 & 37.977 & \\
\hline \multirow{2}{*}{ Sheehan Disability Score (0-30) } & Control & 50 & 25.18 & 33.354 & \multirow{2}{*}{0.006} \\
\hline & Case & 43 & 53.07 & 55.941 & \\
\hline \multirow{2}{*}{ Satisfaction With Life Score } & Control & 50 & 67.38 & 57.172 & \multirow{2}{*}{0.571} \\
\hline & Case & 43 & 78.23 & 112.964 & \\
\hline
\end{tabular}

Statistically significant difference was found between the case and control groups with respect to the following variables:

1. HADS Anxiety score

2. HADS Depression score

3. HAM-D score 
4. HAM-A score

5. Presumptive stressful life events score

6. Total WHOQOL-BREF

7. Sheehan disability score

Table 14: Nicotine dependence

\begin{tabular}{|c|c|c|c|c|c|c|}
\hline \multirow{3}{*}{ FTND Dependence } & \multicolumn{4}{|c|}{ Group } & \multicolumn{2}{|c|}{ Total } \\
\hline & \multicolumn{2}{|c|}{ Control } & \multicolumn{2}{|c|}{ Case } & \multirow{2}{*}{$\mathbf{N}$} & \multirow{2}{*}{$\%$} \\
\hline & $\mathbf{N}$ & $\%$ & $\mathbf{N}$ & $\%$ & & \\
\hline Very low & 20 & 40.0 & 19 & 44.2 & 39 & 41.9 \\
\hline Low & 1 & 2.0 & 2 & 4.7 & 3 & 3.2 \\
\hline Medium & 1 & 2.0 & 1 & 2.3 & 2 & 2.2 \\
\hline High & 15 & 30.0 & 11 & 25.6 & 26 & 28.0 \\
\hline Very high & 13 & 26.0 & 10 & 23.3 & 23 & 24.7 \\
\hline Total & 50 & 100.0 & 43 & 100.0 & 93 & 100.0 \\
\hline
\end{tabular}

\begin{tabular}{|l|l|}
\hline Chi-Square Test & P-Value \\
\hline Fisher's Exact Test & 0.933 \\
\hline
\end{tabular}

The two groups did not differ significantly with respect to nicotine dependence.

\section{Chart 12:}

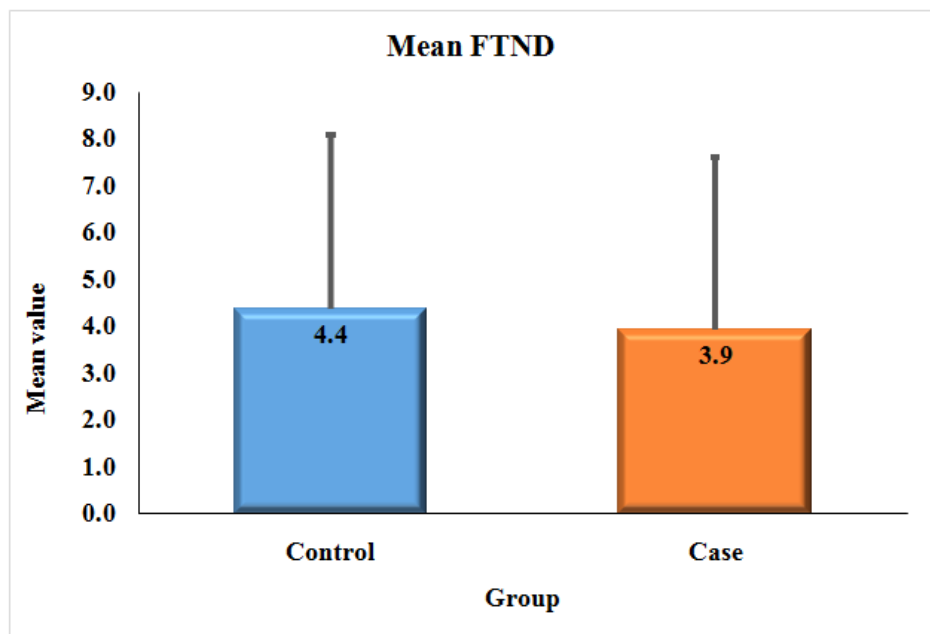

Nicotine dependence pattern was similar between the case and control groups.

\section{Chart 13.}

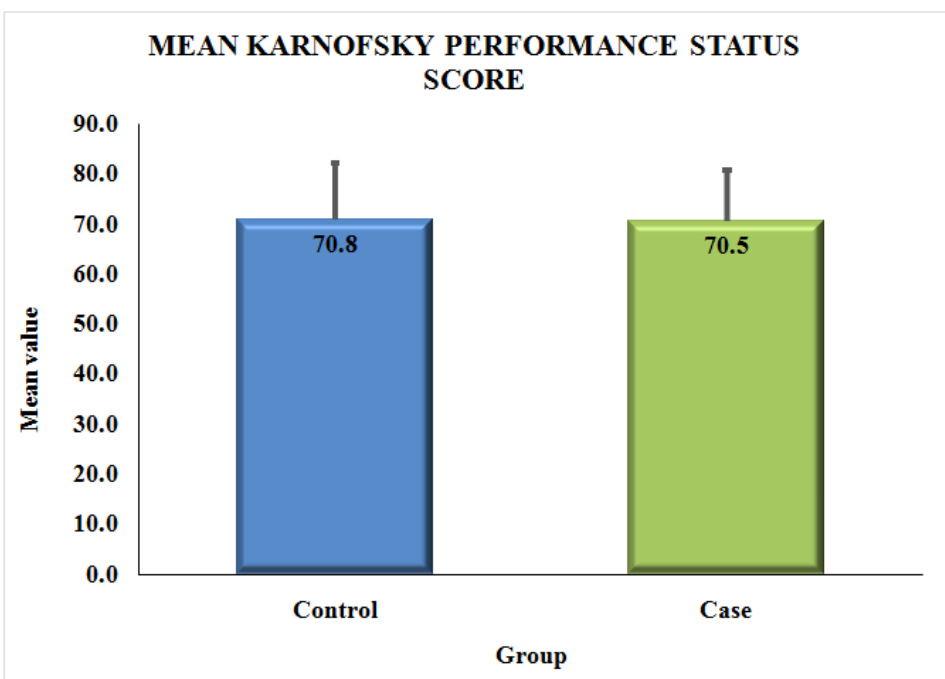

The two groups did not differ significantly in terms of Karnofsky performance status score. 
Chart 14:

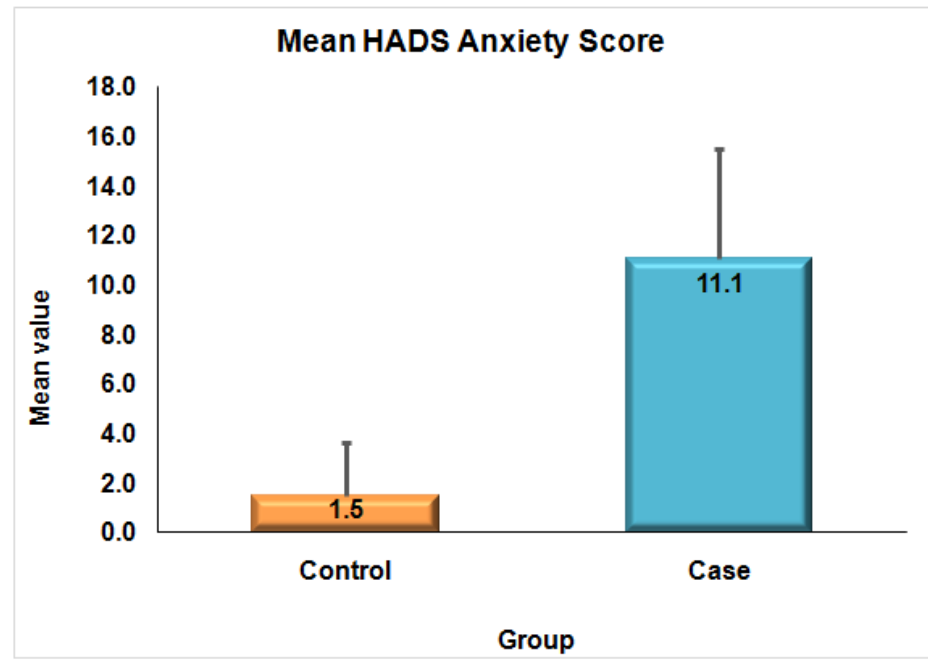

The Mean HADS Anxiety Score was significantly higher in the case group compared to the control group.

\section{Chart 15:}

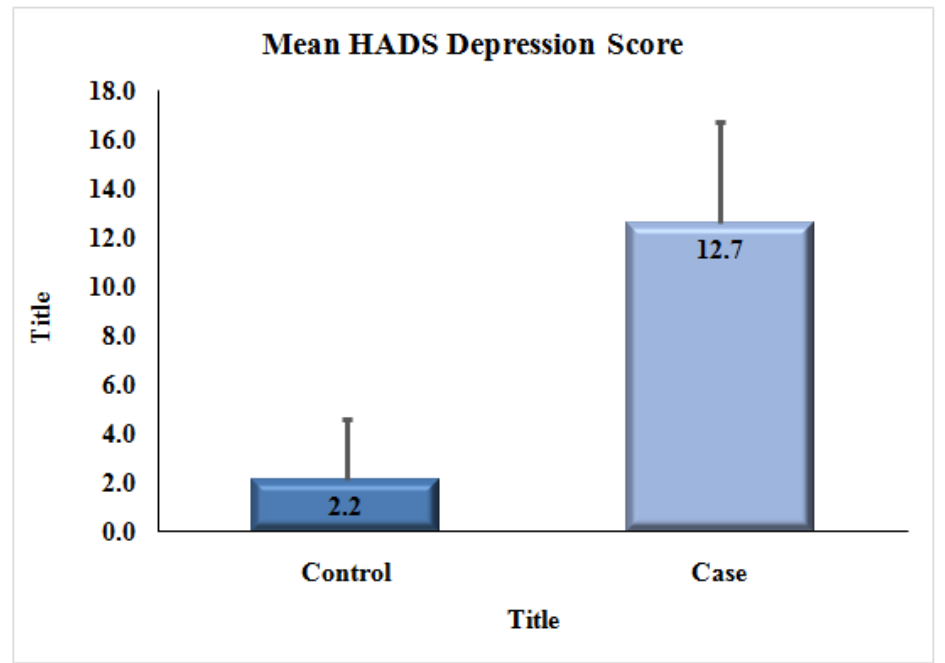

control group.

The Mean HADS Depression Score was significantly high in the case group compared to the

Chart 16: Frequency of anxiety and depression in the study sample based on screening with HADS score

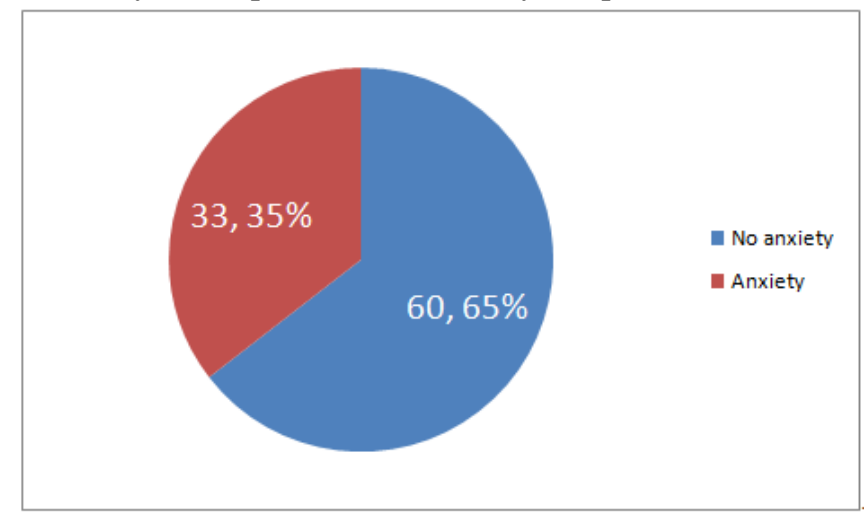

Anxiety

Anxiety (HADS Anxiety Score > 8) was present in 35\% of the subjects. 


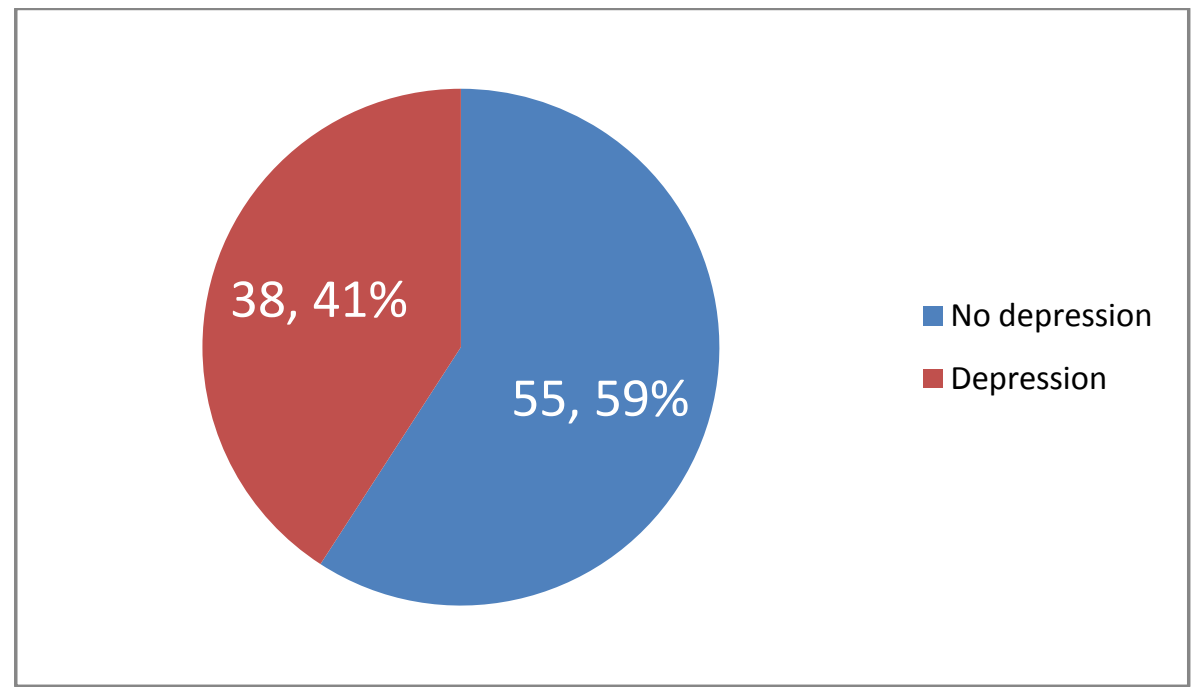

Depression

Depression (HADS Depression Score $>8$ ) was present in $41 \%$ of the subjects.

Table 15: HAM-A score

\begin{tabular}{|l|l|l|l|l|l|l|}
\hline \multirow{2}{*}{ HAMA Level } & \multicolumn{2}{|l|}{ Group } & Case & \multicolumn{2}{l|}{ Total } & \multirow{2}{*}{ N } \\
\cline { 2 - 6 } & Control & \% & N & \% & & \\
\cline { 2 - 7 } & $\mathbf{N}$ & 100.0 & 18 & 41.9 & 68 & 73.1 \\
\hline Mild & 50 & .0 & 7 & 16.3 & 7 & 7.5 \\
\hline Moderate & 0 & .0 & 5 & 11.6 & 5 & 5.4 \\
\hline Severe & 0 & .0 & 13 & 30.2 & 13 & 14.0 \\
\hline Very severe & 0 & 100.0 & 43 & 100.0 & 93 & 100.0 \\
\hline Total & 50 & & & & \\
\hline
\end{tabular}

\begin{tabular}{|l|l}
\hline Chi-Square Test & P-Value
\end{tabular}

\begin{tabular}{l|l}
\hline Fisher's Exact Test & $<\mathbf{0 . 0 0 1}$ \\
\hline
\end{tabular}

There was significant difference between the two groups in terms of HAM-A score. Mild anxiety was most common (41.9\%) followed by very severe anxiety $(30.2 \%)$ in the case group.

Chart 17:

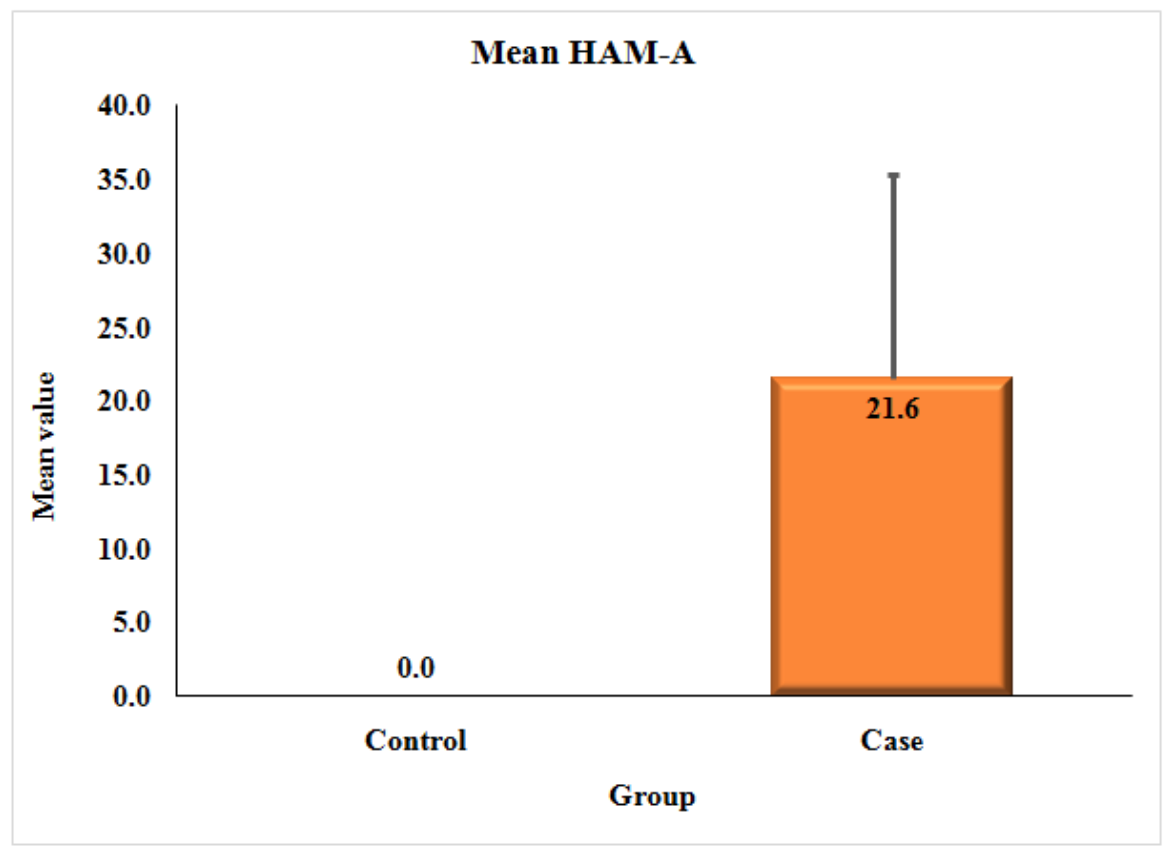

The mean HAM-A score in the case group was 21.6 
Table 16: HAM-D score

\begin{tabular}{|l|l|l|l|l|l|l|}
\hline \multirow{2}{*}{ HAMD Level } & \multicolumn{2}{|l|}{ Group } & \multicolumn{2}{l|}{ Case } & \multicolumn{2}{l|}{ Total } \\
\cline { 2 - 6 } & Control & N & \multirow{2}{*}{} \\
\cline { 2 - 6 } & $\mathbf{N}$ & $\mathbf{\%}$ & $\mathbf{N}$ & $\mathbf{\%}$ & & \\
\hline Normal & 50 & 100.0 & 4 & 9.3 & 54 & 58.1 \\
\hline Mild & 0 & .0 & 3 & 7.0 & 3 & 3.2 \\
\hline Moderate & 0 & .0 & 6 & 14.0 & 6 & 6.5 \\
\hline Severe & 0 & .0 & 3 & 7.0 & 3 & 3.2 \\
\hline Very severe & 0 & .0 & 27 & 62.8 & 27 & 29.0 \\
\hline Total & 50 & 100.0 & 43 & 100.0 & 93 & 100.0 \\
\hline
\end{tabular}

\begin{tabular}{|l|l|}
\hline Chi-Square Test & P-Value \\
\hline Fisher's Exact Test & $\mathbf{< 0 . 0 0 1}$ \\
\hline
\end{tabular}

There was significant difference between the two groups in terms of HAM-D score. Very severe depression was most common (62.8\%) followed by moderate depression (14\%) in the case group

\section{Chart 18:}

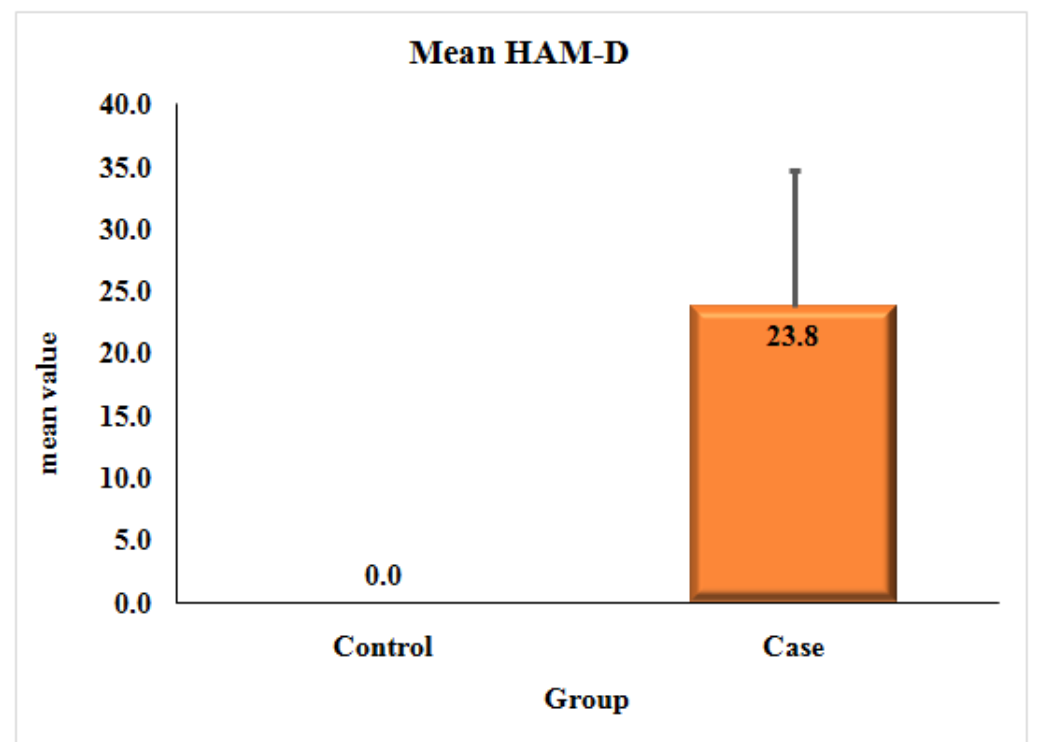

The mean HAM-D score in the case group was 23.8

Chart 19: Social Support Questionnaire scores

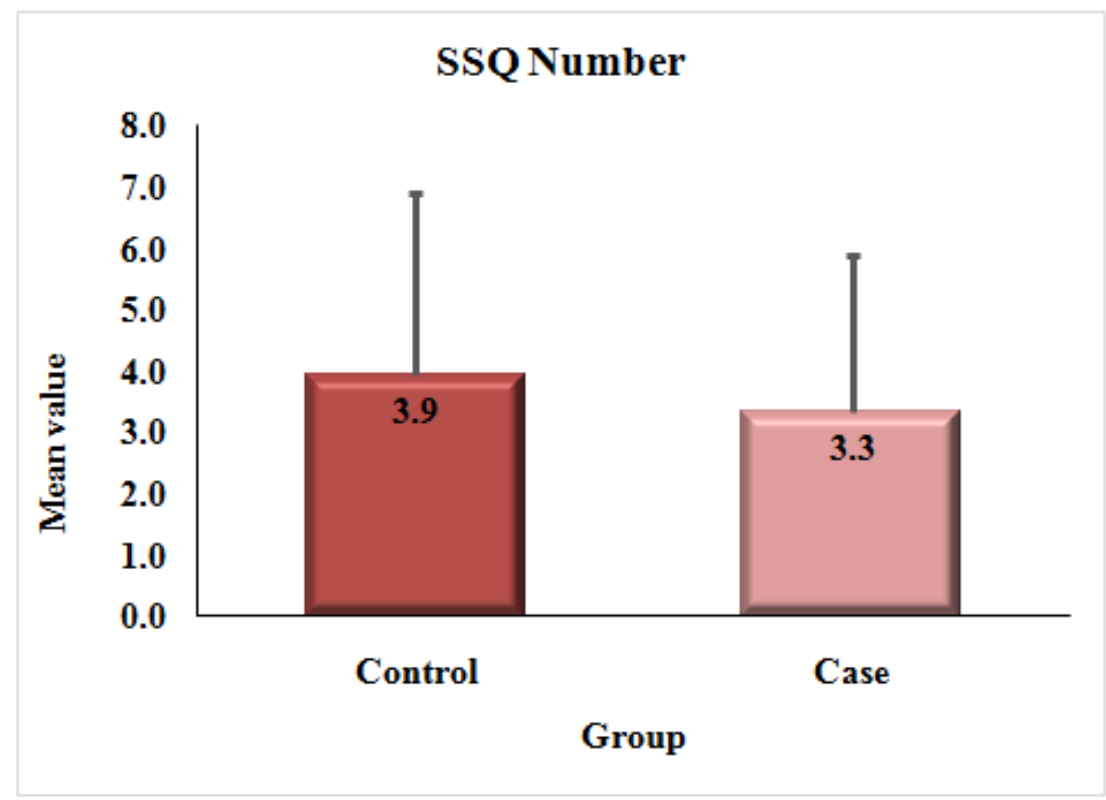




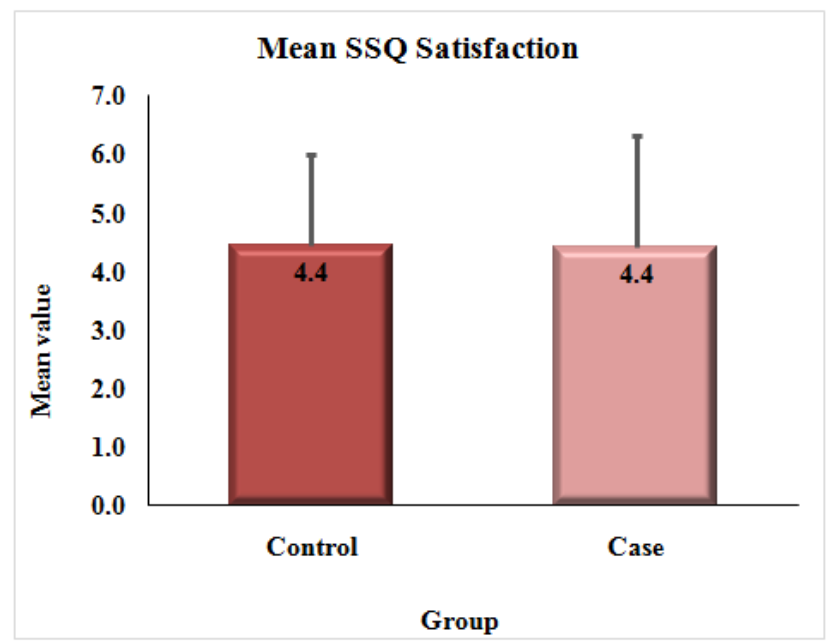

The two groups did not differ significantly in terms of both Number and Satisfaction subscales of the Social Support Questionnaire.

\section{Chart 20:}

MEAN PRESUMPTIVE STRESSFUL LIFE EVENTS SCORE

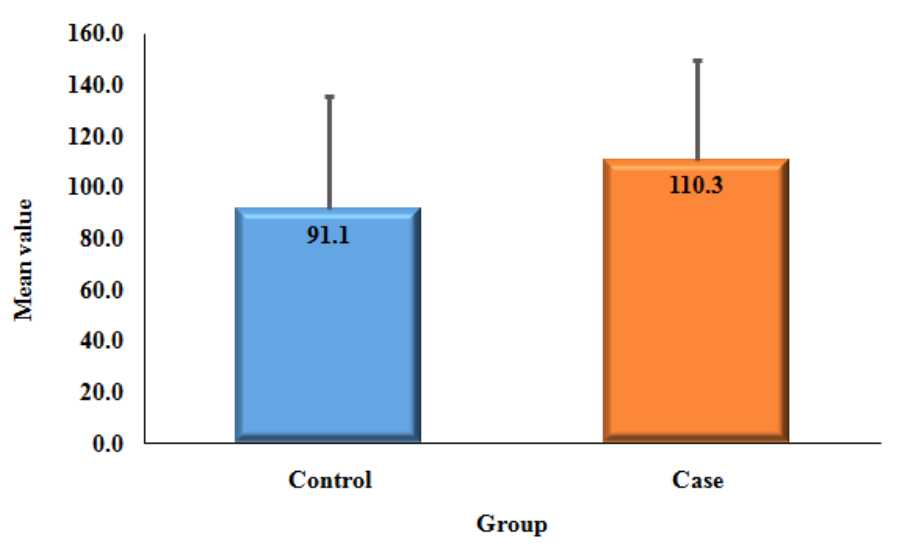

Significantly higher stressful life events scores were observed in the case group compared to the control group.

Chart 21:

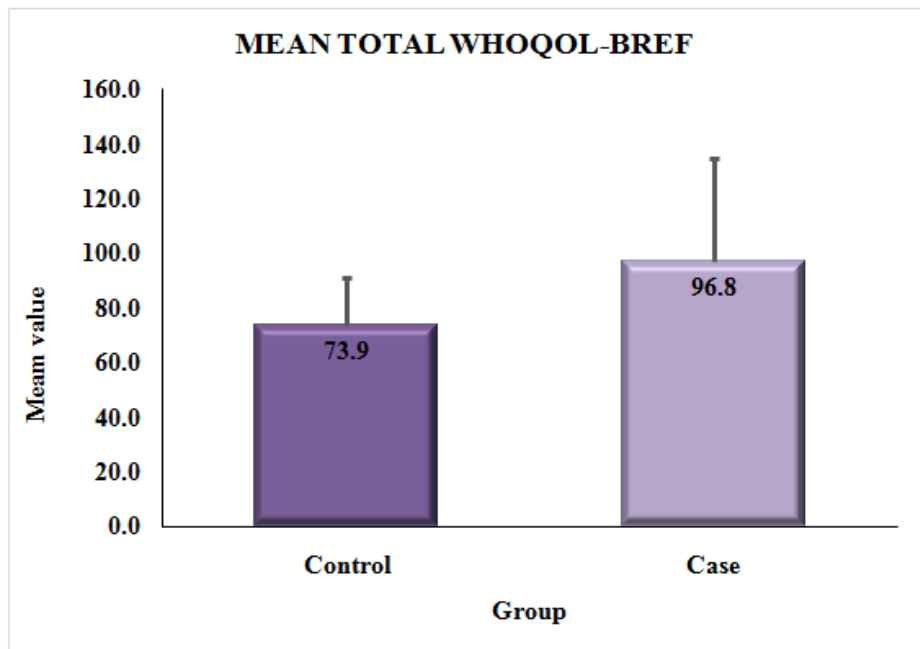

Significantly higher Total WHOQOL-BREF scores were observed in the case group compared to the control group. 


\section{Discussion}

The objective of the study was to evaluate the association of certain sociodemographic and illness related factors with depression and anxiety in a group of patients with lung cancer. The factors to be studied were selected after reviewing earlier studies which indicated some variables to be more frequently linked to psychological distress in patients with cancer. These factors have been summarized by Holland (1993).

\section{Selection of the sample population for the study}

The factors gender, age and phase of illness were all considered as variables in the study. Because cancer is a heterogenous condition we did not want to study all cancers, keeping type of cancer as a variable. This was so decided because the findings in one type of cancer can't be generalized to all other types of malignancy. Hence we decided to confine our study to the prevalence and predictors of depression and anxiety in patients with non-small cell lung cancer. This group of 93 consisted of the patients consecutively admitted in the Medical Oncology ward in Rajiv Gandhi Government General Hospital, Chennai during the specified period and more sample size couldn't be collected due to time constraint.

The patients were seen in a tertiary referral hospital setup. Most of them had been referred there with long duration of illness, after failed attempts at treatment or for more advanced therapy.

\section{Prevalence of depression and anxiety}

With respect to anxiety, 33 subjects (i.e. 35\%) scored above 8 in HADS Anxiety subscale and hence were considered as cases. False negatives among the remaining 60 controls (i.e. $65 \%$ ) were avoided by subjecting them to clinical interview using the SCID. The prevalence rate of $35 \%$ in the study is on the higher side compared to previous studies. Akechi et al (2001) found the prevalence of anxiety to be $18 \%$ in their study. Mendonsa and Appaya (2010) found the figure of $17 \%$.

With respect to depression, 38 subjects (i.e. 41\%) scored above 8 in HADS Depression subscale and hence were considered as cases. False negatives among the remaining 55 controls (i.e. 59\%) were avoided by subjecting them to clinical interview using the SCID. The prevalence rate of $41 \%$ in the study is on the higher side compared to previous studies. Bukberg et al (1994) had found in their study $24 \%$ prevalence of severe depression and 18\% prevalence of moderate depression. Hegel et al (2006) found depression in 11\% of their study subjects. Akechi et al (2001) reported a figure of $14 \%$ in their study. Kugaya et al (2000) found out a prevalence of $17 \%$ in their study subjects. Massie MJ (1990) reported 25\% prevalence in hospital admitted patients with cancer. Mendonsa and Appaya (2010) found out 26\% frequency of depression in their study. A prevalence of $14 \%$ was reported in an outpatient oncology clinic by Berard et al (1998). Many other previous studies on the prevalence of depression in lung cancer have placed the figure anywhere in the range of $11-44 \%$ (Massie, 2004).

reasons:

The high prevalence of anxiety and depression in this study could be due to the following

1. The criteria used included mild, moderate and severe forms of anxiety and depression.

2. Many of the subjects had recurrence after successful treatment. Recurrence has higher prevalence of depression compared to the primary therapy of terminal stage groups (Silberfarb, 1980). Thus, it is evident that many high risk factors for depression and anxiety being inherent in the chosen sample could have led to the high prevalence rate.

3. The criteria didn't exclude somatic symptoms in the patients which was very high as found in the study.

4. The reactive element (? Adjustment disorder) couldn't be ruled out.

\section{Illness related variables}

The present study found an increased frequency of the most common symptoms seen in cancer patients i.e. anorexia, fatigue, sleep disturbance, in patients who had scored above the cut-off for being designated as cases. Although this could be expected because it could have been contributed by either depression or cancer or both, it is also possible that persons with underlying dysphoric mood may perceive more somatic symptoms (Endicott, 1984). The study also revealed that phase of illness has a bearing upon being depressed or anxious. It has revealed that the advanced phase 4, with its attendant complications was significantly associated with depression and anxiety. This could probably be due to the fact that there is more physical disability in this phase compared to the phases 1 and 2 .

\section{Time since diagnosis}

Mean time since diagnosis was found in our study to be 16 months in the case group compared to 24 months in the control group. Probably, the additional symptom burden of depression and/anxiety affected response to treatment and hence referral to tertiary care at an earlier time in these patients. 


\section{Presumptive stressful life events score}

The presumptive stressful life events score was significantly higher in cases compared to controls. This could be due to additional life stressors resulting secondarily due to the cancer or its diagnosis, for eg., loss of job.

\section{Total WHOQOL-BREF score}

The quality of life score was actually significantly higher in our study in the case group compared with the control group. This is an unexpected finding and we are unable to find an explanation for this.

\section{Sheehan Disability score}

The disability score was significantly higher in the cases compared to the controls. This is probably due to the fact that most subjects in the case group were in advanced phase of cancer (phase 4) and this led to more physical complications which in turn led to more disability.

\section{LIMITATIONS}

1. Small sample size.

2. Cross-sectional study design- This limited the chances of predicting future possibility of depression and anxiety based on current anxiety and depression scale scores.

3. Overlap of somatic symptoms of cancer with those of depression.

4. Personality factors were not taken into account as a variable mediating anxiety and/or depression in these patients.

5. Coping through religious beliefs, which is thought to be universally important (Jenkins, 1995), was not assessed systematically.

6. Cognitive impairment was not assessed with measures rigorous enough to determine its influence on depression and/or anxiety.

\section{Interventions in cancer patients}

\section{Suggestions}

\section{Detection of depression and/or anxiety by the cancer care team}

The study shows certain factors like recurrence of symptoms and functional status to be associated with increased risk for depression and/or anxiety in cancer patients. Increasing the sensitivity of health personnel caring for these patients to these factors could lead to earlier interventions.

The HADS is found to be a useful instrument for screening purpose. The measurement is simple and can be easily administered by non-mental health personnel. It could thus be used routinely to screen patients in this high risk group.

The sensitivity among the professionals in palliative care centres and pain clinics to detect depression/anxiety and institute appropriate management or referral needs to be increased.

\section{Patient education and providing information to caregivers}

The meaning which the patient attributes to his symptoms could alter his perceptions about the nature of the illness and lead to psychological distress. Hence, explaining the origin of symptoms, its meaning and correlation with disease status would alleviate distress to a great extent. This pattern of explanation should become routine with all patients.

\section{Training the treating team in psychosocial management}

Specific psychotherapeutic skills of listening, providing psychological support, group work, talking about death, etc., should be provided through practical training programs like workshops.

\section{Future Directions}

1. The study has demonstrated the relationship between depression/anxiety and various other factors like physical disability, phase of cancer, etc., Studies in future need to assess each of these factors in depth.

2. Longitudinal studies (cohort and case-control) following patients from date of initial presentation are needed.

3. Studies are needed to clarify whether tendencies toward having negative cognitive distortions predispose patients with cancer to develop depression. This may help in planning interventions based on cognitivebehavioral models.

4. The spiritual domain of coping which is an important coping strategy has to be assessed after developing scales that are applicable to the Indian social situation. 
5. More than self-report scales, in-depth interviews, case studies and other qualitative methods of research would be valuable in exploring concepts and processes which are part of this domain.

6. There is a dearth of studies on depression and/anxiety in lung cancer patients which needs to be addressed in the future.

\section{Conclusion}

1. The prevalence of depression and anxiety in lung cancer patients in this tertiary hospital inpatient population was found to be $41 \%$ and $35 \%$ respectively.

2. The major risk factors for depression and anxiety in lung cancer patients as found in the study were presence of concomitant life stressors, advanced cancer phase and higher disability.

3. The observation of the association of some factors other than the illness requires interventions of psychosocial nature with all patients. Specifically, there is need to explore the personal meaning of cancer symptoms, of terminality, death and dependency from the individual and socio-cultural context of sufferers of malignancy. Efforts must be made to provide this help along with medical care to all patients. This necessitates close liaison between the fields of Psychiatry and Oncology leading to the flowering of the branch of Psycho-oncology.

\section{Bibliography}

[1]. Agarwal M, Hamilton JB, Moore CE and Crandell JL. (2010) Predictors of Depression Among Older African American Cancer Patients, Cancer Nurs. 33(2): 156-163. doi:10.1097/ NCC.0b013e 3181bdef76

[2]. Akechi T, Nakano T, Okamura H, Ueda S, Akizuki N, Nakanishi T, Yoshikawa E, Matsuki H, Hirabayashi E, Uchitomi Y. (2001) Psychiatric Disorders in Cancer Patients: Descriptive Analysis of 1721 Psychiatric Referrals at Two Japanese Cancer Center Hospitals, JJCO; 31(5)188 194

[3]. Akechi T, Okuyama T, Uchida M, Nakaguchi T, Sugano K, Kubota Y, Ito Y, Kizawa Y, Komatsu H. (2012) Clinical Indicators of Depression among Ambulatory Cancer Patients Undergoing Chemotherapy, Jpn J Clin Oncol;42(12)1175-1180

[4]. Alcalar N, Ozkan S, Kucucuk S, Aslay I, Ozkan M. (2012) Association of Coping Style, Cognitive Errors and Cancer-related Variables with Depression in Women Treated for Breast Cancer, Jpn J Clin Oncol;42(10)940-947

[5]. Arnold SD, Forman LM, Brigidi BD, Carter KE, Schweitzer HA, Quinn HE, Guill AB, Herndon JE, Raynor RH. (2008) Evaluation and characterization of generalized anxiety and depression in patients with primary brain tumors, Neuro-Oncology $10,171-181$

[6]. Arrieta O, Angulo LP, Núñez-Valencia C, Dorantes-Gallareta Y, Macedo EO, Martínez-López D, Alvarado S, Corona-Cruz JF, Oñate-Ocaña LF. (2013) Association of Depression and Anxiety on Quality of Life, Treatment Adherence, and Prognosis in Patients with Advanced Non-small Cell Lung Cancer, Ann Surg Oncol;20(6):1941-8

[7]. Arun K., S.K. Chaturvedi, Geetha D. (2011) Symptom distress, depression and quality of life in advanced cancer patients, Free Papers. Indian J Psychiatry; 53:27-72

[8]. Ashbury FD, Madlensky L, Raich P, Thompson M, Whitney G, Hotz K, Kralj B, Edell WS(2003) Antidepressant prescribing in community cancer care. Support Care Cancer, 11:278-285

[9]. Bailey RK, Geyen DJ, Scott-Gurnell K, Hipolito MMS, Bailey TA, Beal JM. (2005) Understanding and treating depression among cancer patients. Int J Gynecol Cancer, 15:203-208

[10]. Bardwell WA, Natarajan L, Dimsdale JE, Rock CL, Mortimer JE, Hollenbach K, Pierce JP (2006) Objective cancer-related variables are not associated with depressive symptoms in women treated for early-stage breast cancer. J Clin Oncol, 24(16):2420-7

[11]. Berard RM, Boermeester F, Viljoen G. (1998) Depressive disorders in an out-patient oncology setting: prevalence, assessment, and management, Psychooncology; $7(2): 112-20$

[12]. Berard RM. (2001) Depression and anxiety in oncology: the psychiatrist's perspective, J Clin Psychiatry; 62 Suppl 8:58-61; discussion 62-3

[13]. Bjordal K, Kaasa S. (1995) Psychological distress in head and neck cancer patients 7-11 years after curative treatment, British Journal of Cancer, 71, 592-597

[14]. Blumberg EM, West PM, Ellis FW. (1954) A Possible Relationship between Psychological Factors and Human Cancer, Psychosomatic Medicine, vol. XVI, no. 4

[15]. Brennan J. (2001) Adjustment to cancer-coping or personal transition? Psycho-Oncology, 10:1-18

[16]. Bukberg J, Penman D, Holland JC (1984) Depression in Hospitalized Cancer Patients, Psychosomatic Medicine Vol. 46, No. 3

[17]. Burgess C, Cornelius V, Love S, Graham J, Richards M, Ramirez A. (2005) Depression and anxiety in women with early breast cancer: five year observational cohort study. BMJ, 330:702-707

[18]. Chaturvedi SK. (2012) Psychiatric Oncology: Cancer in mind, Indian J Psychiatry;54:111-8

[19]. Chen ML, Chen MC, Yu CT. (2011) Depressive symptoms during the first chemotherapy cycle predict mortality in patients with advanced non-small cell lung cancer, Support Care Cancer;19(11):1705-11. doi: 10.1007/s00520-010-1005-8

[20]. Cho J, Choi EK, Kim SY, Shin DW, Cho BL, Kim CH, Koh DH, Guallar E, Bardwell WA, Park JH. (2013) Association between cancer stigma and depression among cancer survivors: a nationwide survey in Korea, Psychooncology. doi: 10.1002/pon.3302

[21]. Chowdhury B, Mondal DK, Bhattacharyya S. (2011) A study on psychological distress in cancer patient, Posters. Indian J Psychiatry;53:73-109

[22]. Costanzo ES, Lutgendorf SK, Sood AK, Anderson B, Sorosky J, Lubaroff DM. (2005) Psychosocial factors and interleukin-6 among women with advanced ovarian cancer. Cancer, 15, 104(2):305-13

[23]. Coyne JC, Palmer SC, Shapiro PJ, Thompson R, De ichele A. (2004) Distress, psychiatric morbidity, and prescriptions for psychotropic medication in breast cancer waiting room sample. Gen Hosp Psychiatry, 26:121-128.

[24]. Deimling GT, Bowman KF, Sterns S, Wagner LJ, Kahana B. (2006) Cancer-related health worries and psychological distress among older adult, long-term cancer survivors, Psychooncology; 15(4):306-20

[25]. Diener, E., Emmons, R. A., Larsen, R. J., Griffin, S. (1985). The Satisfaction with Life Scale. Journal of Personality Assessment, $49,71-75$ 
[26]. Du-Quiton J, Wood PA, Burch JB, Grutsch JF, Gupta D, Tyer K, Lis CG, Levin RD, Quiton DF, Reynolds JL, Hrushesky WJ. (2010) Actigraphic assessment of daily sleep-activity pattern abnormalities reflects self-assessed depression and anxiety in outpatients with advanced non-small cell lung cancer, Psychooncology;19(2):180-9. doi: 10.1002/pon.1539

[27]. Ell K, Sanchez K, Vourlekis B, Lee PJ, Dwight-Johnson M, Lagomasino I, Muderspach L, Russell C. (2005) Depression, correlates of depression, and receipt of depression care among low-income women with breast or gynecologic cancer. J Clin Oncol, 23:30523060

[28]. Ellis J, Lin J, Walsh A, Lo C, Shepherd FA, Moore M, Li M, Gagliese L, Zimmermann C, Rodin G. (2009) Predictors of referral for specialized psychosocial oncology care in patients with metastatic cancer: the contributions of age, distress, and marital status. $J$ Clin Oncol;27(5):699-705

[29]. Endicott E. (1984) Measurement of depression in patients with cancer. Cancer 2:243-249, 1984 (suppl)

[30]. Ernstmann N, Neumann M, Ommen O, Galushko M, Wirtz M, Voltz R, Hallek M, Pfaff H. (2009) Determinants and implications of cancer patients' psychosocial needs. Support Care Cancer; $17(11): 1417-23$

[31]. Fafouti M, Paparrigopoulos T, Zervas Y, Rabavilas A, Malamos N, Liappas I, Tzavara C. Depression, Anxiety and General Psychopathology in Breast Cancer Patients: A Cross-sectional Control Study, in vivo 24: 803-810

[32]. Faller H, Bülzebruck H, Drings P, Lang H. (1999) Coping, distress and survival among patients with lung cancer. Arch Gen psychiatry, 56:756-762

[33]. Friedman GD. (1990) Depression, Worry, and the Incidence of Cancer, AJPH November 1990, Vol. 80, No. 11

[34]. Giannousi Z, Gioulbasanis I, Pallis AG, Xyrafas A, Dalliani D, Kalbakis K, Papadopoulos V, Mavroudis D, Georgoulias V, Papandreou CN. (2011) Nutritional status, acute phase response and depression in metastatic lung cancer patients: correlations and association prognosis. Support Care Cancer;20(8):1823-9

[35]. Grassi L, Rosti G. (1999) Psychiatric and psychosocial concomitants of abnormal illness behaviour in patients with cancer. Psychother Psychosom, 65:246-252

[36]. Hamer M, Chida Y, Molloy GJ. (2009) Psychological distress and cancer mortality, J Psychosom Res;66(3):255-8. doi: 10.1016/j.jpsychores.2008.11.002

[37]. Hamilton, M. (1959), The assessment of anxiety states by rating. British Journal of Medical Psychology, 32: 50-55

[38]. Hamilton M. (1960) A rating scale for depression, J. Neurol. Neurosurg. Psychiat., 23, 56

[39]. Heatherton TF, Kozlowski LT, Frecker RC, Fagerström KO. The Fagerström Test for Nicotine Dependence: a revision of the Fagerström Tolerance Questionnaire. Br J Addict;86(9):1119-27

[40]. Hegel MT, Moore CP, Collins ED, Kearing S, Gillock KL, Riggs RL, Clay KF, Ahles TA. (2006) Distress, Psychiatric Syndromes, and Impairment of Function in Women With Newly Diagnosed Breast Cancer, Cancer;107:2924-31

[41]. Hinz A, Krauss O, Stolzenburg JU, Schwalenberg T, Michalski D, Schwarz R. (2009) Anxiety and depression in patients with prostate cancer and other urogenital cancer: a longitudinal study, Urol Oncol;27(4):367-72

[42]. Holland JC. (1993) Principles of psycho-oncology. In Cancer Medicine ( $3^{\text {rd }}$ ed.) Holland JF, Frei E, Bast RC et al. (eds.) Lea \& Febiger, Philadelphia. 1019-1033

[43]. Holland JC. (2003) Psychological Care of Patients: Psycho-Oncology's Contribution, Journal of Clinical Oncology, Vol 21, No 23s (December 1 Supplement), 2003: pp 253s-265s

[44]. Hopwood P, Stephens RJ. (2000) Depression in Patients With Lung Cancer: Prevalence and Risk Factors Derived From Quality-ofLife Data, J Clin Oncol 18:893-903

[45]. Jadoon NA, Munir W, Shahzad MA, Choudhry ZS. (2010) Assessment of depression and anxiety in adult cancer outpatients: a cross sectional study, BMC Cancer, 10:594

[46]. Jehn CF, Kuehnhardt D, Bartholomae A, Pfeiffer S, Krebs M, Regierer AC, Schmid P, Possinger K, Flath BC. (2006) Biomarkers of depression in cancer patients, Cancer, 1;107(11):2723-9

[47]. Jenkins RA, Pargament KI. (1995) Religion and Spirituality as Resources for Coping with Cancer, Journal of Psychosocial Oncology;13:51-74

[48]. Kadan-Lottick NS, Vanderwerker LC, Block SD, Zhang B, Prigerson HG. (2005) Psychiatric disorders and mental health service use in patients with advanced cancer. Cancer 2005, 104(12):2872-81

[49]. Karnofsky DA, Burchenal JH. (1949) The clinical evaluation of chemotherapeutic agents in cancer. In Evaluation of chemotherapeutic agents. Edited by MacLeod CM. New York: Columbia University Press;191-205

[50]. Kissane D. (2009) Beyond the psychotherapy and survival debate: the challenge of social disparity, depression and treatment adherence in psychosocial cancer care. Psychooncology; 18(1):1-5

[51]. Korfage IJ, Essink-Bot ML, Janssens AC, Schroder FH, de Koning HJ. (2006) Anxiety and depression after prostate cancer diagnosis and treatment: 5-year follow-up. Br J Cancer, 94(8):1093-8

[52]. Kroenke K, Zhong X, Theobald D, Wu J, Tu W, Carpenter JS. (2010) Somatic Symptoms in Cancer Patients with Pain and/or Depression Prevalence, Disability, and Health Care Use, Arch Intern Med; 170(18): 1686-1694

[53]. Kronfol Z, Silva J, Greden J, Dembinski S, Carroll BJ. (1982) Cell-mediated immunity in melancholia, Psychosomatic Medicine, 44,304

[54]. Kugaya A, Akechi T, Okuyama T, Nakano T, Mikami I, Okamura H, Uchitomi Y. (2000) Prevalence, Predictive Factors, and Screening for Psychologic Distress in Patients with Newly Diagnosed Head and Neck Cancer, Cancer 2000;88:2817-23

[55]. Kurtz ME, Kurtz JC, Stommel M, Given CW, Given B. (2002) Predictors of depressive symptomatology of geriatric patients with colorectal cancer: a longitudinal view, Support Care Cancer;10(6):494-501

[56]. Li S, Wang Y, Xin S, Cao J. (2012) Changes in Quality of Life and Anxiety of Lung Cancer Patients Underwent Chemotherapy, Chinese J Lung Cancer, Volume 15, Issue 8, Pages 465-470

[57]. Linn B, Linn M, Jensen J. (1982) Degree of depression and immune responsiveness. Psychosomatic Medicine, 44, 128-9

[58]. Lloyd-Williams M. (1994) Depression among cancer patients, British Journal of General Practice, May 1994, pp. 233-34

[59]. Massie MJ, Holland JC. (1990) Depression and the cancer patient, J Clin Psychiatry; 51 Suppl:12-7; discussion 18-9

[60]. Massie MJ. (2004) Prevalence of Depression in Patients With Cancer, J Natl Cancer Inst Monogr;32:57-71

[61]. Mathieson CM, Logan-Smith LL, Phillips J, Macphee M. (1996) Caring for head and neck oncology patients: Does social support lead to better quality of life? Can Fam Physician; 42:1712-1720

[62]. Mendonsa RD, Appaya P. Psychiatric morbidity in outpatients of gynecological oncology clinic in a tertiary care hospital. Indian $J$ Psychiatry 2010;52:327-32

[63]. Montazeri A. (2008) Health-related quality of life in breast cancer patients: A bibliographic review of the literature from 1974 to 2007, Journal of Experimental \& Clinical Cancer Research, 27:32 
[64]. Musselman DL, Miller AH, Porter MR, Manatunga A, Gao F, Penna S, Pearce BD, Landry J, Glover S, McDaniel JS, Nemeroff CB (2001) Higher than normal plasma interleukin-6 concentrations in cancer patients with depression: Preliminary findings. Am J Psychiatry, 158:1252-1257

[65]. Nakada S, Nagao K, Takiguchi Y, Tatsumi K, Kuriyama T. (1996) Quality of Life and Anxiety before and after Lung Cancer Chemotherapy: Relationship to Patient's Personality, Internal Medicine 35: 611-616

[66]. Nelson CJ, Weinberger MI, Balk E, Holland J, Breitbart W, Roth AJ. (2009) The Chronology of Distress, Anxiety, and Depression in Older Prostate Cancer Patients, The Oncologist, 14:891-899

[67]. Nordin K, Glimelius B. (1999) Predicting delayed anxiety and depression in patients with gastrointestinal cancer, British Journal of Cancer, 79(3/4), 525-529

[68]. Okamura M, Yamawaki S, Akechi T, Taniguchi K, Uchitomi Y. (2002) Psychiatric disorders following breast cancer recurrence: prevalence, associated factors and relationship to quality of life. Jpn J Clin Oncol, 35(6):302-309

[69]. Onitilo AA, Nietert PJ, Egede LE. (2006) Effect of depression on all cause mortality in adults with cancer and differential effects by cancer site. Gen Hosp Psychiatry, 28(5):396-402

[70]. Pandey M, Sarita GP, Devi N, Thomas BC, Hussain BM, Krishnan R. (2006) Distress, anxiety, and depression in cancer patients undergoing chemotherapy, World Journal of Surgical Oncology, 4:68

[71]. Pasquini M, Biondi M. (2007) Depression in cancer patients: a critical review, Clinical Practice and Epidemiology in Mental Health, 3:2 doi:10.1186/1745-0179-3-2

[72]. Passik SD, Dugan W, McDonald MV, Rosenfeld B, Theobald DE, Edgerton S. (1998) Oncologists' recognition of depression in their patients with cancer, J Clin Oncol;16(4):1594-600

[73]. Peck A, Boland L. (1972) Emotional reactions to having cancer. Am Roentgenol Radia Ther Nucl Med;114:591-9

[74]. Pinquart M, Duberstein PR. (2010) Depression and cancer mortality: a meta-analysis, Psychol Med; 40(11): 1797-1810. doi:10.1017/S003329170999228

[75]. Pirl WF, Traeger L, Greer JA, Bemis H, Gallagher E, Lennes I, Sequist L, Heist R, Temel JS. (2011) Tumor Epidermal Growth Factor Receptor Genotype and Depression in Stage IV Non-Small Cell Lung Cancer, The Oncologist, 16:1299-1306

[76]. Pirl WF, Greer JA, Traeger L, Jackson V, Lennes IT, Gallagher ER, Cruz PP, Heist RS, Temel JS. (2012) Depression and Survival in Metastatic Non-Small-Cell Lung Cancer: Effects of Early Palliative Care, JCO , vol. 30 no. 12 1310-1315

[77]. Prieto JM, Atala J, Blanch J, Carreras E, Rovira M, Cirera E, Espinal A, Gasto C. (2005) Role of Depression as a predictor of mortality among cancer patients after stem-cell transplantation. J Clin Oncol, 23:6063-6071

[78]. Raison C, Miller A: Depression in cancer: new developments regarding diagnosis and treatment. Biol Psychiatry 2003, 54:283-294

[79]. Reisine S, Morse DE, Psoter WJ, Eisenberg E, Cohen D, Cleveland D, Mohit-Tabatabai M. (2005) Sociodemographic Risk Indicators for Depressive Symptoms Among Persons With Oral Cancer or Oral Epithelial Dysplasia, J Oral Maxillofac Surg; 63(4): 513-520

[80]. Sarason et al. (1987) A brief measure of social support: Practical and theoretical implications, Journal of Social and Personal Relationships, Vol 4, 497-510

[81]. Sarna L, Padilla G, Holmes C, Tashkin D, Brecht ML, Evangelista L. (2002) Quality of Life of Long-Term Survivors of NonSmall-Cell Lung Cancer, J Clin Oncol 20:2920-2929

[82]. Sharpe M, Strong V, Allen K, Rush R, Postma K, Tulloh A, Maguire P, House A, Ramirez A, Cull A. (2004) Major depression in outpatients attending a regional cancer centre: screening and unmet treatment needs. Br J Cancer, 90(2):314-20

[83]. Sheehan DV, Harnett-Sheehan K, Raj BA. (1996) The measurement of disability, Int Clin Psychopharmacol;11 Suppl 3:89-95

[84]. Shimizu K, Nakaya N, Saito-Nakaya K, Akechi T, Yamada Y, Fujimori M, Ogawa A, Fujisawa D, Goto K, Iwasaki M, Tsugane S, Uchitomi Y. (2012) Clinical biopsychosocial risk factors for depression in lung cancer patients: a comprehensive analysis using data from the Lung Cancer Database Project, Annals of Oncology; 23(8):1973-9

[85]. Silberfarb PM, Maurer LH, Crouthamel CS. (1980) Psychological aspects of neoplastic disease, I: Functional status of breast cancer patients during different treatment regimens. Am J Psychiatry, 137: 450-455

[86]. Singh G, Kaur D, Kaur H. (1984) Presumptive Stressful Life Events Scale (PSLES) - A new Stressful Life Events Scale for use in India, Indian J Psychiatry; 26(2): 107-114

[87]. Spencer R, Nilsson M, Wright A, Pirl W, Prigerson H. (2010) Anxiety Disorders in Advanced Cancer Patients: Correlates and Predictors of End of Life Outcomes, Cancer; 116(7): 1810-1819

[88]. Spiegel and Kato. (1996) Psychosocial Influences on Cancer Incidence and Progression, Harvard Review of Psychiatry, 4(1):10-26

[89]. Strong V, Waters R, Hibberd C, Rush R, Cargill A, Storey D, Walker J, Wall L, Fallon M, Sharp M. (2007) Emotional distress in cancer patients: the Edinburgh Cancer Centre symptom study, British Journal of Cancer 96, 868 - 874

[90]. Tavoli A, Mohagheghi MA, Montazeri A, Roshan R, Tavoli Z, Omidvari S. (2007) Anxiety and depression in patients with gastrointestinal cancer:does knowledge of cancer diagnosis matter? BMC Gastroenterology, 7:28

[91]. Ǘstün TB. (1999) The global Burden of mental health disorders. American Journal of Public Health, 89:1315-1318

[92]. Walker J, Sawhney A, Hansen CH, Symeonides S, Martin P, Murray G, Sharpe M. (2013) Treatment of depression in people with lung cancer: A systematic review, Lung Cancer 79, 46-53

[93]. Warmenhoven F, van Rijswijk E, Engels Y, Kan C, Prins J, van Weel C,Vissers K. (2011) The Beck Depression Inventory (BDI-II) and a single screening question as screening tools for depressive disorder in Dutch advanced cancer patients, Support Care Cancer, 20:319-324

[94]. Wedding U, Koch A, Rohrig B, Pientka L, Sauer H, Hoffken K, Maure I. (2007) Requestioning depression in patients with cancer: Contribution of somatic and affective symptoms to Beck's Depression Inventory, Annals of Oncology 18: 1875-1881

[95]. Weinberger MI, Roth AJ, Nelson CJ. (2009) Untangling the Complexities of Depression Diagnosis in Older Cancer Patients, Oncologist; 14(1): 60-66

[96]. WHO International Consortium in Psychiatric Epidemiology. (2000) Cross-national comparisons of prevalences and correlatesof mental disorders. Bulletin of World Health Organization, 78:413-26.

[97]. Williams S, Dale J. (2006) The effectiveness of treatment for depression/depressive symptoms in adults with cancer: a systematic review, British Journal of Cancer, 94, 372 - 390

[98]. World Health Organization. (2004) The World Health Organization Quality of Life (WHOQOL)-BREF

[99]. Zabora J, Blanchard CG, Smith ED, et al.(1997) Prevalence of psychological distress among cancer patients across the disease continuum. J Psychosoc Oncol, 15:73-87

[100]. Zigmond, AS; Snaith, RP (1983). "The hospital anxiety and depression scale". Acta Psychiatrica Scandinavica 67 (6): $361-370$ 